\title{
A Numerical Study on the Diversion Mechanisms of Fracture Networks in Tight Reservoirs with Frictional Natural Fractures
}

 \\ Yanxin Tan ${ }^{4}$ \\ 1 School of Mechanical Engineering, Beijing Key Laboratory of Pipeline Critical Technology and Equipment \\ for Deepwater Oil \& Gas Development, Beijing Institute of Petrochemical Technology, Beijing 102617, China; \\ upcwdb@bipt.edu.cn (D.W.); sundongliang@bipt.edu.cn (D.S.); handongxubox@bipt.edu.cn (D.H.) \\ 2 School of Aeronautic Science and Engineering, Beihang University, Beijing 100083, China \\ 3 Jiangsu Key Laboratory of Advanced Manufacturing Technology, Huaiyin Institute of Technology, \\ Huai'an 223003, China; shifang@hyit.edu.cn \\ 4 The Conventional Natural Gas Research Institute, China Univeristy of Petroleum, Beijing 102249, China; \\ lixiuhui031@foxmail.com (X.L.); tyx2285@foxmail.com (Y.T.) \\ * Correspondence: 0020150031@bipt.edu.cn; Tel.: +86-10-8129-2136 \\ + Current address: 19 Qing-yuan North Road, Huang-cun, Da-xing District, Beijing 102617, China. \\ $\ddagger \quad$ These authors contributed equally to this work.
}

Received: 25 September 2018; Accepted: 31 October 2018; Published: 5 November 2018

\begin{abstract}
An opened natural fracture (NF) intercepted by a pressurized hydro-fracture (HF) will be diverted in a new direction at the tips of the original NF and subsequently form a complex fracture network. However, a clear understanding of the diversion behavior of fracture networks in tight reservoirs with frictional NFs is lacking. By means of the extended finite element method(XFEM), this study investigates the diversion mechanisms of an opened NF intersected by an HF in naturally fractured reservoirs. The factors affecting the diversion behavior are intensively analyzed, such as the location of the NF, the horizontal principal stress difference, the intersection angle between HF and NF, and the viscosity of the fracturing fluid. The results show that for a constant length of NF $(7 \mathrm{~m})$ : (1) the upper length of the diverted fracture (DF) decreases by about $2 \mathrm{~m}$ with a $2 \mathrm{~m}$ increment of the upper length of NF ( $\left.L_{\text {upper }}\right)$, while the length of DF increases $9.06 \mathrm{~m}$ with the fluid viscosity increased by $99 \mathrm{mPa} \cdot \mathrm{s}$; (2) the deflection angle in the upper parts increases by $30.8^{\circ}$ with the stress difference increased by $5 \mathrm{MPa}$, while the deflection angle increases by $61.2^{\circ}$ with the intersection angle decreased by $30^{\circ}$. It is easier for the opened NF in lower parts than that in upper parts to be diverted away from its original direction. It finally diverts back to the preferred fracture plane (PFP) direction. The diversion mechanisms of the fracture network are the results of the combined action of all factors. This will provide new insight into the mechanisms of fracture network generation in tight reservoirs with NFs.
\end{abstract}

Keywords: hydraulic fracturing; tight reservoirs; fracture diversion; extended finite element method; fracture network

\section{Introduction}

With the technological progress in petroleum industries, petroleum engineers are increasingly concerned with the exploration and development of tight reservoirs in recent years. Due to the ultra-low matrix permeability, hydraulic fracturing is a key technology for enhancing the recovery of tight hydrocarbon reservoirs [1-11]. Activation of preexisting natural fractures (NFs) during fracturing 
treatment is favorable for creating complex fracture networks. The interaction between a hydraulic fracture (HF) and an NF is a complex coupled process, which involves rock deformation, fluid flow, and fracture diversion [12-21].

When an HF intercepts an NF during a hydro-fracking treatment, three scenarios-arrest, offset, and cross-are observed. Renshaw and Pollard developed a criterion to describe the mechanical NF-HF interaction when they were perpendicular to each other [22]. Gu et al. afterwards proposed an extended Renshaw-Pollard criterion at nonorthogonal intersection angles on the basis of the experimental results of hydraulic fracturing for Colton sandstone [23]. This crossing criterion has been extensively applied in the mathematical models of stimulated reservoir volume (SRV) fracturing in shale gas wells. Various numerical techniques such as finite difference, discrete element, and finite element methods have been presented to investigate the mechanical interaction between HF and NF [16,24-26]. Based on the finite element software ABAQUS 6.14, Chen et al. developed a cohesive zone finite element-based model to investigate the NF-HF interaction complexity, which took into account the interface friction of weak planes [24]. Based on the discrete element method (DEM) model, Zou et al. numerically investigated HF network propagation in shale formations, and the plastic deformation in hydraulic fracturing was considered [25]. Wu and Wong used a numerical manifold method (NMM) to capture the strong discontinuity across the crack face, and this method could smoothly handle the problems of fracture network propagation [26]. However, the above-mentioned numerical methods have the drawback that crack paths should be predefined a priori. Therefore, crack cannot be freely extended on mesh grids if the direction of crack propagation is not known in advance. By means of a diffusive phase-field modeling approach, Heider et al. introduced a numerical framework of $\mathrm{HF}$ in tight rocks, but this simulation could be time-consuming because it requires a very fine mesh [27].

The extended finite element method (XFEM), which introduces additional enrichment functions to account for the jump across the crack surfaces and the singularity of stress in the vicinity of crack tips, provides a powerful tool to simulate the hydraulic fracturing problem. Its great advantage is that crack propagation is not mesh-dependent. Some scholars such as Dahi-Taleghani, Mao, and Gordeliy have done a great deal of innovative research on hydraulic fracturing simulation [28-32] in past decades, but some assumptions, such as a constant fluid pressure, were made to deal with the mechanical NF-HF interaction in order to simplify the complex precess. Recently, Shi and Wang successfully modeled the connection of two cracks by means of additional junction enrichment and by sharing pore pressure nodes at intersection points [33,34]. Using the combined method of XFEM and DEM, Ghaderi et al. concluded that the tensile and shear breakage of NFs were a function of angle and distance from an induced fracture [35]. Paul et al. developed a mixed linear cohesive law, which relies on a stable mortar formalism, and utilized the XFEM method to simulate the non-planar HF propagation [36]. Based on the XFEM technique, Remij et al. applied the enhanced local pressure (ELP) model to investigate crack interaction in hydraulic fracturing by assuming multiple discontinuities in the domain [37]. Vahab and Khalili used an XFEM penalty method, which was embedded in Kuhn-Tucker inequalities, to model multi-zone fracking treatments within saturated porous media [38].

It is well known that an HF usually has a non-planar crack growth (refereed to fracture diversion) by a stress shadow effect [39-44]. An opened NF intercepted by an HF will be diverted in a new direction at the tips of the original NF and subsequently form a complex fracture network $[33,34,45,46]$. However, a clear understanding of the diversion behavior of fracture network in tight reservoirs with frictional NFs is lacking [47]. In particular, the effect of factors such as the location of the NF, the horizontal stress difference, and the intersection angle between HF and NF on the mechanical diversion behavior of HFs is not clear at present. Therefore, with the XFEM technique [48-51], a numerical simulation on the diversion mechanisms of a fracture network in naturally fractured reservoirs was studied. This study focuses on the diversion propagation behavior in the vicinity of the two crack tips of the opened NF after an HF intersects with an NF. This will provide new insight on the mechanisms of fracture network formation in tight formations with pre-existed frictional NFs. 


\section{Problem Formulation}

\subsection{Governing Equations of Hydraulic Fracturing Problems}

As shown in Figure 1, the domain $\Omega$ denotes a tight reservoir, which includes an HF and an NF. The injection point is located on the middle left of the domain $\Omega$, and the corresponding pump rate is denoted by $Q_{0}$. As is known, the hydraulic fracturing problem is essentially a fluid-solid interaction process, so its governing equations consist of two parts: the stress equilibrium equation for rock skeleton and fluid pressure equation in the hydraulically driven fracture [52-54].

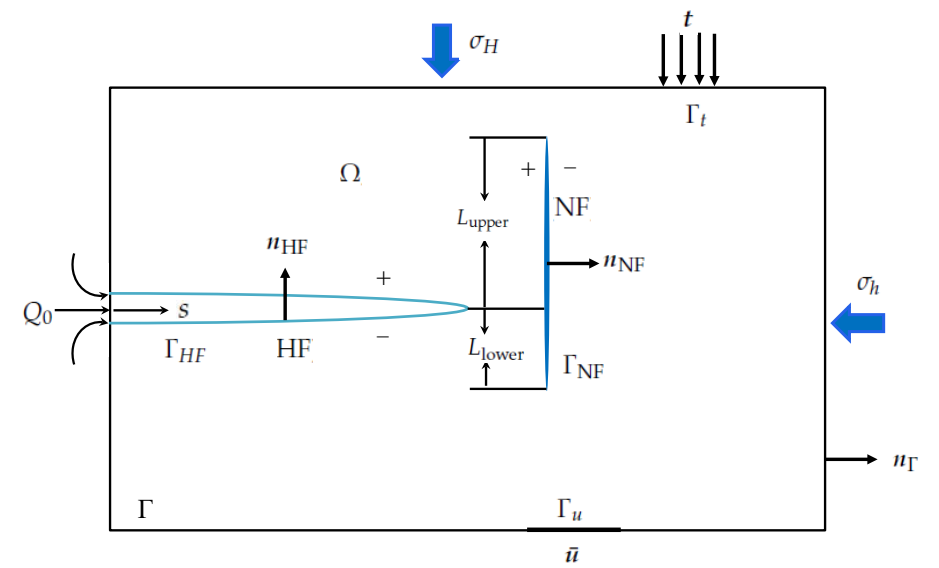

Figure 1. Schematic diagram of a hydro-fracture (HF) intersection with a natural fracture (NF).

(1) The Stress Equilibrium Equation: According to the theory of elasticity, the stress equilibrium equation is expressed:

$$
\nabla \cdot \sigma+\boldsymbol{b}=\mathbf{0} \quad \text { in } \Omega,
$$

where $\sigma$ denotes the stress tensor; $\boldsymbol{b}$ denotes the body force vector in the rock skeleton. As shown in Figure 1, the boundary conditions are composed of a displacement boundary condition $\left(\Gamma_{\mathrm{u}}\right)$ and a force boundary condition $\left(\Gamma_{\mathrm{t}}\right)$. They are expressed as

$$
\left\{\begin{array}{l}
\boldsymbol{u}=\overline{\boldsymbol{u}} \quad \text { on } \Gamma_{\mathrm{u}} \\
\boldsymbol{\sigma} \cdot \boldsymbol{n}=\boldsymbol{t}, \quad \text { on } \Gamma_{\mathrm{t}}, \\
\boldsymbol{\sigma} \cdot \boldsymbol{n}_{\mathrm{HF}}=p \boldsymbol{n}_{\mathrm{HF}}, \quad \text { on } \Gamma_{\mathrm{HF}} \\
\boldsymbol{\sigma} \cdot \boldsymbol{n}_{\mathrm{NF}}=\boldsymbol{t}_{\mathrm{NF}}, \quad \text { on } \Gamma_{\mathrm{NF}}
\end{array}\right.
$$

where $p$ denotes the fluid pressure on the artificial fracture; $t_{\mathrm{NF}}$ denotes the contact traction vector on the NF surface $\Gamma_{\mathrm{NF}} ; \bar{u}$ denotes the displacement imposed on the boundary $\Gamma_{\mathrm{u}} ; \boldsymbol{t}$ denotes the traction vector imposed on the boundary $\Gamma_{t}$.

For brittle rocks, there is a linear relationship between stress tensor and strain tensor under a small deformation assumption, so the corresponding constitutive equation is expressed as

$$
\sigma=D: \varepsilon
$$

where $\boldsymbol{D}$ denotes the fourth elasticity tensor; $\varepsilon$ denotes the strain tensor; the symbol ":" denotes the double dot product of the two tensors.

Under the assumption of small deformation, the relationship between displacement vector $\boldsymbol{u}$ and strain tensor $\varepsilon$ are as follows:

$$
\boldsymbol{\varepsilon}=\frac{1}{2}\left[\nabla \boldsymbol{u}+(\nabla \boldsymbol{u})^{T}\right] .
$$


(2) Fluid Pressure in an HF: Under lubrication theory assumptions, the velocity profile of the fluid in the HF is that of a planar Poiseuille flow between two parallel plates. Therefore, the fluid pressure in the HF can be expressed as $[15,33,34,55,56]$

$$
\frac{\partial w}{\partial t}-\frac{\partial}{\partial s}\left(k \frac{\partial p}{\partial s}\right)=0
$$

where $w$ denotes the fracture opening of HF; $s$ denotes the crack propagation direction; $t$ denotes the injection time; $k$ denotes the fracture transmissivity.

According to the cubic law, the fracture transmissivity can be expressed as

$$
k=\frac{w^{3}}{12 \mu}
$$

where $\mu$ denotes the viscosity of fracturing fluid.

The corresponding initial and boundary conditions can be expressed as

$$
\left\{\begin{array}{l}
w(s, 0)=0, \\
w\left(s_{\text {tip }}, 0\right)=0, \\
q(0, t)=Q_{0} \\
q\left(s_{\text {tip }}, 0\right)=0,
\end{array}\right.
$$

where $s_{\text {tip }}$ denotes the tips of HFs; $q$ denotes the injection rate of fracturing fluid at the crack point $s$ and time $t$.

It is can be seen that Equation (7) satisfies mathematically the Neumann boundary condition. In order to get a unique solution for the fluid pressure equation, the constraint condition should be additionally imposed. The necessary condition, i.e., the conservation of global mass in the HF can be written as

$$
\int_{0}^{s_{t i p}} w d s-\int_{0}^{t} Q_{0} d t=0
$$

\subsection{Crack Propagation Criterion}

According to the theory of fracture mechanics, the maximum circumferential stress criterion is adopted to determine the propagation direction of a hydraulically driven fracture at every time $t$. The artificial fracture will propagate along a direction perpendicular to the maximum circumferential stress. If the stress intensify factor $K$ is no less than the fracture toughness of rock skeleton $K_{\mathrm{IC}}$, the crack will propagate along a certain direction. The interaction integral method in domain form is utilized to calculate the stress intensity factors $K_{\mathrm{I}}$ and $K_{\mathrm{II}}$. The following equation of the interaction integral can be written as [57]

$$
I^{(1,2)}=\int_{A}\left[\sigma_{i j}^{(1)} \frac{\partial u_{i}^{2}}{\partial x_{1}}+\sigma_{i j}^{(2)} \frac{\partial u_{i}^{1}}{\partial x_{1}}-W^{(1,2)} \delta_{1 j}\right] \frac{\partial q_{w}}{\partial x_{j}} d A,
$$

where $I^{(1,2)}$ denotes the interaction integral; $W^{(1,2)}$ denotes the interaction strain energy as follows; $q_{w}(\boldsymbol{x})$ denotes the smooth weighting function, which takes a value from 0 to $1 ; \delta$ denotes the Kronecker symbol; the superscripts (1) and (2), respectively, denote the current state and the auxiliary state for the stress and strain field. The corresponding calculation procedures can be described in detail in $[40,57,58]$

$$
W^{(1,2)}=\sigma_{i j}^{(1)} \varepsilon_{i j}^{(2)}=\sigma_{i j}^{(2)} \varepsilon_{i j}^{(1)} .
$$

The direction of crack propagation $\theta$ can be computed in a local tip coordinate system:

$$
\theta=2 \arctan \left[\frac{1}{4}\left(\mathrm{~K}_{\mathrm{I}} / \mathrm{K}_{\mathrm{II}}+\sqrt{\left.\mathrm{K}_{\mathrm{I}} / \mathrm{K}_{\mathrm{II}}\right)^{2}+8}\right)\right],
$$


where the symbol "arctan" denotes the arc-tangent function.

\subsection{The Cross Criterion between HF and Frictional NF}

As is known, when an HF encounters a frictional NF, there are three possible scenarios: arrested, direction-crossing, or a crossing with an offset $[16,23,41]$. Here, the extended Renshaw and Pollard rule is adopted to determine the interaction behavior between HF and NF. As shown in Figure 2, if a new fracture initiates on the opposite side of the NF, the maximum principle stress $\sigma_{1}$ will reach the rock tensile stress. Meanwhile, a no-slip condition should be satisfied along the NF surface. Otherwise, the HF will cross directly or branch into NF with an offset. The expressions of the combined shear stress and normal stress are shown in Equation (12), which is described in detail in other references [15,23].

$$
\left\{\begin{array}{l}
\sigma_{1}=T_{0}, \\
\tau_{\beta}<S_{0}-\mu_{f} \sigma_{\beta y},
\end{array}\right.
$$

where $\beta$ denotes the intersection angle between HF and NF; $\tau_{\beta}$ denotes the combined shear stress on the NF surface under the action of remote stress and the local crack tip stress; $\sigma_{\beta y}$ denotes the combined normal stress; $T_{0}$ denotes the rock tensile strength; $S_{0}$ denotes the cohesion force of the frictional NF; $\mu_{f}$ denotes the frictional coefficient of the NF surface.

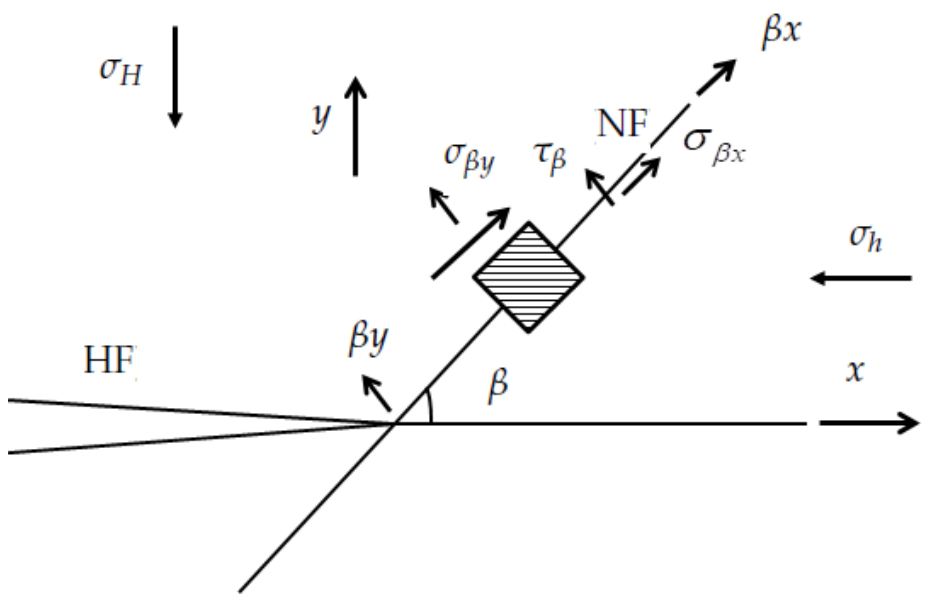

Figure 2. An HF approaching the NF.

\subsection{XFEM and Discretization of the Governing Equations of the Hydraulic Fracturing Problem}

The XFEM (extended finite element method) is utilized to approximate the displacement discontinuity on both sides of the HF. In order to represent the multiple cracks, a Junction enrichment function is introduced, as shown in Figure 3. The enriched displacement field can be written as [59].

$$
\begin{aligned}
& \boldsymbol{u}(\boldsymbol{x})=\sum_{I \in N} N_{I}(\boldsymbol{x}) \boldsymbol{u}_{I}+\sum_{j=1}^{M^{d i s}} \sum_{J \in N^{d i s}} N_{J}(\boldsymbol{x})\left[H(\boldsymbol{x})-H\left(\boldsymbol{x}_{J}\right)\right] a_{I} \\
& +\sum_{k=1}^{M^{t i p}} \sum_{K \in N^{t i p}} N_{K}(\boldsymbol{x}) \sum_{\alpha=1}^{4}\left[\Psi_{\text {tip }}^{\alpha}(\boldsymbol{x})-\Psi_{\text {tip }}^{\alpha}\left(\boldsymbol{x}_{K}\right)\right] b_{K}^{\alpha} \\
& +\sum_{l=1}^{M^{j u n}} \sum_{L \in N^{j u n}} N_{L}(\boldsymbol{x})\left[J^{H}(\boldsymbol{x})-J^{H}\left(\boldsymbol{x}_{L}\right)\right] c_{L},
\end{aligned}
$$

where $N, N^{\text {dis }}, N^{t i p}$ and $N^{j u n}$, respectively, denote the set of standard nodes, Heaviside enrichment nodes, crack-tip nodes, and junction enrichment nodes; $\boldsymbol{u}$ denotes the standard nodal d.o.f. (degrees of freedom); $a_{I}, b_{K}^{\alpha}(\alpha=1,4)$, and $c_{L}$, respectively, denote the corresponding enriched nodal d.o.f.; $M^{\text {dis }}$ denotes the number of cracks including the main cracks and the secondary cracks; $M^{\text {tip }}$ denotes 
the number of crack tips; $M^{j u n}$ denotes the number of junctions with $M^{j u n}=M^{\text {dis }}-1 ; H(x)$ denotes the Heaviside enrichment function; $J^{H}(x)$ denotes the junction enrichment function; $\Psi(x)$ denotes the crack-tip enrichment function; $N_{I}, N_{J}, N_{K}$, and $N_{L}$ denote the standard shape function of node $I, J, K$, and $L$, respectively.

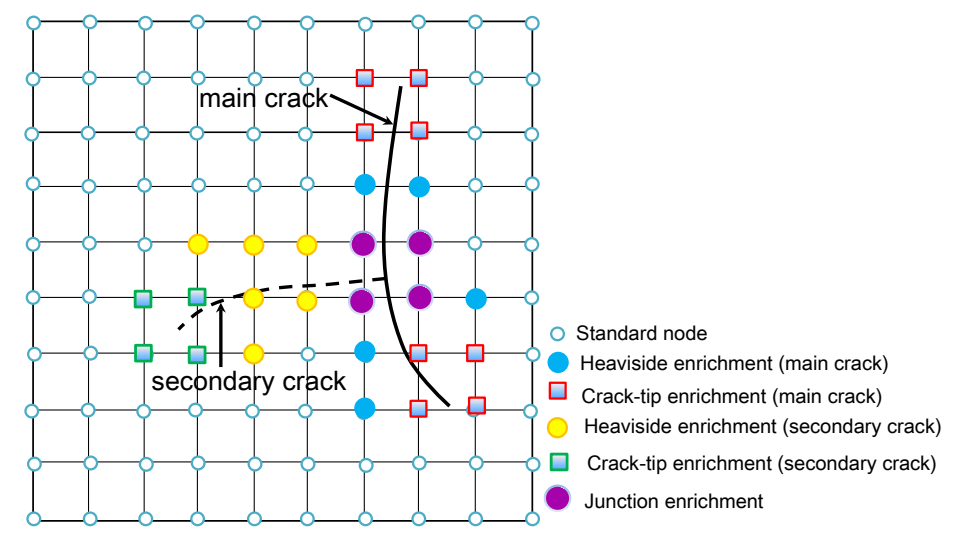

Figure 3. The discontinuous junction function for multiple cracks.

The Heaviside enrichment function is expressed as [59]

$$
H(x)= \begin{cases}0, \text { if } & x<0 \\ 1, \text { if } & x \geq 0\end{cases}
$$

The crack-tip enrichment function is defined as

$$
\left\{\Psi_{t i p}^{\alpha}(r, \theta)\right\}_{\alpha=1}^{4}=\left\{\sqrt{r} \sin \frac{\theta}{2}, \sqrt{r} \cos \frac{\theta}{2}, \sqrt{r} \sin \theta \sin \frac{\theta}{2}, \sqrt{r} \sin \theta \cos \frac{\theta}{2}\right\},
$$

where $(r, \theta)$ denotes the local crack-tip coordinate in the polar coordinate system.

The junction enrichment function $J^{H}(\boldsymbol{x})$ is defined as

$$
J^{H}(\boldsymbol{x})=\left\{\begin{array}{l}
H\left(\varphi^{s}(\boldsymbol{x})\right), \text { if } \varphi^{m}(\boldsymbol{x})<0 \\
0, \text { if } \varphi^{m}(\boldsymbol{x})>0
\end{array}\right.
$$

where $\varphi^{m}(\boldsymbol{x})$ and $\varphi^{S}(\boldsymbol{x})$, respectively, denote the signed distance function of the main crack and the secondary crack. It can be seen that $J^{H}(x)$ is equal to $1,-1$, or 0 on different sub-domains divided by the secondary cracks.

According to the finite element method, the pressure field $p$ and the fracturing opening displacement vector $w$ can be respectively approximated as

$$
\begin{gathered}
\boldsymbol{w}=\sum_{I \in S_{w}} N_{I}^{w} \boldsymbol{u}_{I}=\boldsymbol{N}^{w}(s) \boldsymbol{U}, \\
p(s)=\sum_{I \in S_{H F}} N_{I}^{p} \boldsymbol{p}_{I}=\boldsymbol{N}^{p}(s) \boldsymbol{P},
\end{gathered}
$$

where $U$ and $P$, respectively, denote the global nodal displacement vector and the nodal pressure vector; $N^{p}(s)$ and $N^{w}(s)$, respectively, denote the matrix of the shape function of the fracture opening and pressure. 
By substituting the above XFEM formulation, displacement and pressure approximations into the weak form of stress equilibrium equation and lubrication equation, the corresponding discretization forms are written as

$$
\begin{gathered}
K U-Q P-F^{e x t}=\mathbf{0}, \\
Q^{T} \Delta U+\Delta t \boldsymbol{H P}+\Delta t S=\mathbf{0},
\end{gathered}
$$

where $K$ denotes the global stiffness matrix; $Q$ denotes the coupling matrix; $F^{\text {ext }}$ denotes the external loading vector; $\boldsymbol{H}$ denotes the flow matrix; $\Delta t$ denotes the time step; and $S$ denotes the source term. They are, respectively, defined as follows [33,34]:

$$
\begin{aligned}
\boldsymbol{K} & =\left[\begin{array}{cc}
\int_{\Omega}\left(\boldsymbol{B}^{\text {std }}\right)^{T} \boldsymbol{D}\left(\boldsymbol{B}^{\text {std }}\right) d \Omega & \int_{\Omega}\left(\boldsymbol{B}^{\text {std }}\right)^{T} \boldsymbol{D}\left(\boldsymbol{B}^{\text {enr }}\right) d \Omega \\
\int_{\Omega}\left(\boldsymbol{B}^{\text {enr }}\right)^{T} \boldsymbol{D}\left(\boldsymbol{B}^{s t d}\right) d \Omega & \int_{\Omega}\left(\boldsymbol{B}^{\text {enr }}\right)^{T} \boldsymbol{D}\left(\boldsymbol{B}^{\text {enr }}\right) d \Omega+\int_{\Gamma_{N F}}\left(\boldsymbol{N}^{w}\right)^{T} \boldsymbol{D}^{\text {cont }}\left(\boldsymbol{N}^{w}\right) d \Gamma
\end{array}\right] \\
& =\left[\begin{array}{cc}
\boldsymbol{K}_{s s} & \boldsymbol{K}_{s e} \\
\boldsymbol{K}_{e s} & \boldsymbol{K}_{e e}+\boldsymbol{K}_{e e}^{c o n t}
\end{array}\right] .
\end{aligned}
$$

In the above Equation (21), $D^{\text {cont }}$ denotes the contact stiffness matrix of fracture interfaces:

$$
\begin{gathered}
Q=\int_{\Omega}\left(\boldsymbol{N}^{w}\right)^{T} n_{\Gamma_{N F}}\left(\boldsymbol{N}^{p}\right) d \Omega, \\
\boldsymbol{F}^{e x t}=\int_{\Gamma_{t}}\left(\boldsymbol{N}^{u}\right)^{T} \boldsymbol{t} d \Gamma, \\
\boldsymbol{H}=\int_{\Gamma_{H F}} \frac{\partial \boldsymbol{N}_{p}{ }^{T}}{\partial s} k \frac{\partial \boldsymbol{N}_{p}}{\partial s} d s, \\
\boldsymbol{S}=\left.\boldsymbol{N}_{p}(s)^{T}\right|_{s=0} Q_{0} .
\end{gathered}
$$

As shown in Figure 4, the flow rate in the main crack and secondary crack satisfies the law of conservation, i.e., $Q_{0}=Q_{1}+Q_{2}$, where $Q_{1}$ and $Q_{2}$ denote the flow rate in Branches 1 and 2 of the secondary crack, respectively. The nonlinear fluid-solid coupling system of equations of hydraulic fracturing problems can be numerically solved by the Newton-Raphson method. More details are described in $[33,34]$.

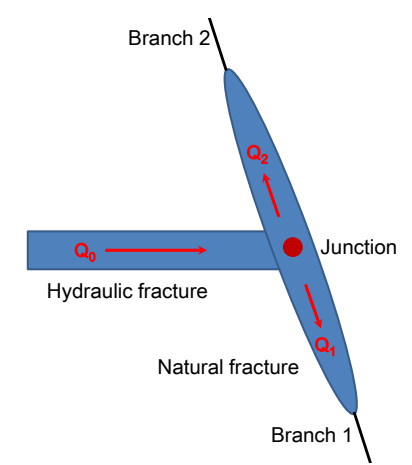

Figure 4. Schematic diagram of a T-shaped fluid-driven fracture.

\section{Results and Discussion}

\subsection{Verification of the XFEM Model}

For the model verification, the results from our models is summarized in Appendix A [33,34]. The verification model of this XFEM code is described in detail in $[33,34]$, so the related process is not repeated in this article. It is shown that the numerical results have good agreement with the experimental results of true tri-axial hydraulic fracturing by TerraTek, Inc. (Salt Lake City, UT, USA). 
For further details of numerical and experimental procedures and the corresponding results, we refer the reader to References [33,34,60,61].

\subsection{Effect of the Location of Natural Fractures on the Diversion of Fracture Network Propagation}

In this section, the effect of the location position of an NF on HF propagation paths is determined by numerical simulation using XFEM. The input parameter values of this model are as shown in Table 1. Under isotropic stress state conditions, the intersection angle between HF and NF is equal to $90^{\circ}$. As shown in Figure 1, the domain is a $25 \mathrm{~m} \times 25 \mathrm{~m}$ square, where the injection point is located at the midpoint of the left edge. In this domain, the HF is $2.6 \mathrm{~m}$ in length, and the length of NF is equal to $7 \mathrm{~m}$. Based on the above input parameters, the mechanical NF-HF interaction processes in hydraulic fracturing are numerically simulated at different lengths of NF in lower and upper parts, i.e., corresponding to $L_{\text {lower }}$ and $L_{\text {upper }}$ in Figure 1, respectively.

Table 1. Input parameter values of the hydro-fracking model.

\begin{tabular}{ll}
\hline Input Parameter & Value \\
\hline Young's Modulus, $E$ & $20 \mathrm{GPa}$ \\
Poisson's ratio, $v$ & 0.2 \\
Rock density, $\rho$ & $2460 \mathrm{~kg} / \mathrm{m}^{3}$ \\
Friction coefficient of NF, $\mu_{\mathrm{f}}$ & 0.3 \\
Cohesion of the NF, $S_{0}$ & $0 \mathrm{MPa}$ \\
Fracture toughness, $K_{\mathrm{IC}}$ & $1.0 \mathrm{MPa} \cdot \mathrm{m}^{\frac{1}{2}}$ \\
Tensile strength, $T_{0}$ & $1.5 \mathrm{MPa}$ \\
Unconfined compression strength, UCS & $100 \mathrm{MPa}$ \\
Apparent viscosity of fracturing fluid, $\mu$ & $0.1 \mathrm{~Pa} \cdot \mathrm{s}$ \\
The consistency index of fracturing fluid, $K$ & $0.84 \mathrm{~Pa} \cdot \mathrm{s}^{\mathrm{n}}$ \\
The flow behavior index of fracturing fluid, $n$ & 0.53 \\
Dynamic viscosity index, $m$ & 2.0 \\
Fluid pump rate, $Q_{0}$ & $0.001 \mathrm{~m}{ }^{2} / \mathrm{s}$ \\
Pore pressure, $P_{0}$ & $5 \mathrm{MPa}$ \\
Maximum horizontal stress, $\sigma_{\mathrm{H}}$ & $5 \mathrm{MPa}$ \\
Minimum horizontal stress, $\sigma_{\mathrm{h}}$ & $5 \mathrm{MPa}$ \\
\hline
\end{tabular}

The corresponding crack propagation paths are as shown in Figure 5. It is obvious that fracture diversion occurs near the tips of the NF in all cases. In Figure 5a, when the HF intersects with the NF, the fracturing fluid flows into the opened NF. In the lower parts of the NF, the opened NF firstly propagates along a vertically downward path for a certain length, and it is then diverted along a new direction; in the upper parts of the NF, the opened NF is directly diverted at the upper tip of the original NF. In Figure 5b, both the lower and upper parts of the NF firstly extend vertically downward and upward for a short distance, respectively, and are then diverted to the right-hand side of the graph. However, the length of the lower parts of the diverted fracture (DF) is longer than that of the upper parts of the DF, corresponding to the red line in Figure 1. In Figure 5c, in the upper parts of the NF, the opened fracture can only propagate vertically upward, and cannot be diverted near the tip of the NF; in the lower parts of the NF, the opened fracture can be diverted away from the original NF. By making use of the data in Figure 5, the length of the DF propagation in the upper parts is calculated from the upper tip of the original NF. When the upper length of NF, i.e., $L_{\text {upper }}$, is equal to 4,5 , and $6 \mathrm{~m}$, the corresponding length is $3.14,2.15$, and $1.14 \mathrm{~m}$, respectively. If $L_{u p p e r}$ is increased by $2 \mathrm{~m}$, the upper length of the DF will decrease by $2 \mathrm{~m}$. Therefore, it is shown that the longer the upper parts of the original NF are, the more difficult it is for the opened NF to be diverted away from the upper tip of the NF under the conditions of an isotropic stress state, while the lower parts of the original NF is more easily diverted to the right-hand side than the upper parts of the original NF under this circumstance. 


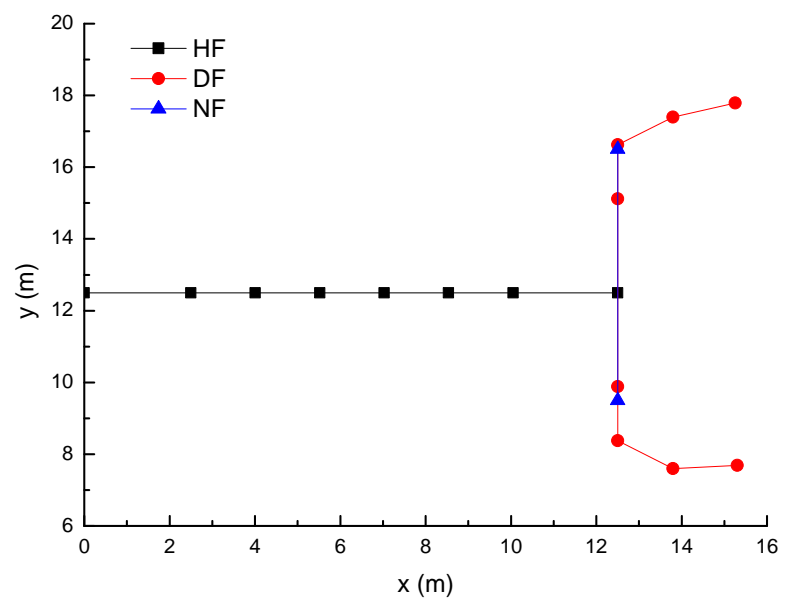

(a) $L_{\text {lower }}=3 \mathrm{~m}, L_{\text {upper }}=4 \mathrm{~m}$

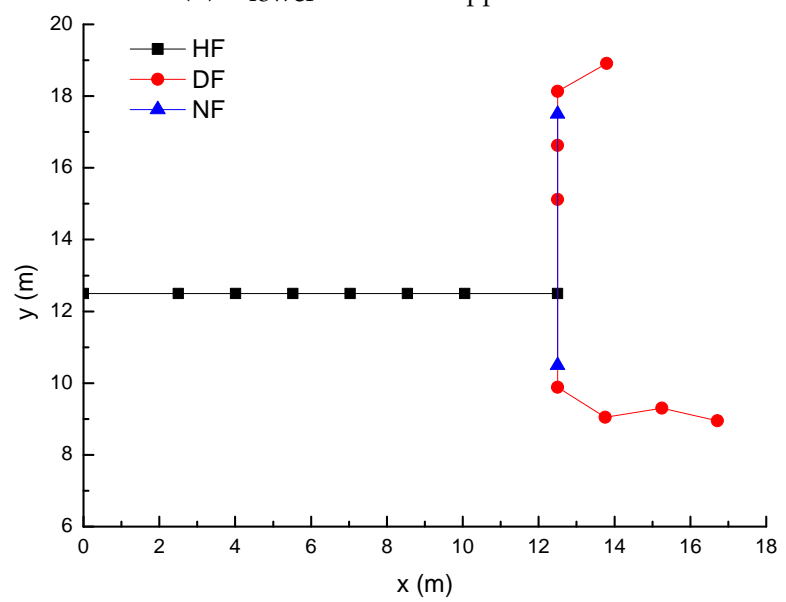

(b) $L_{\text {lower }}=2 \mathrm{~m}, L_{\text {upper }}=5 \mathrm{~m}$

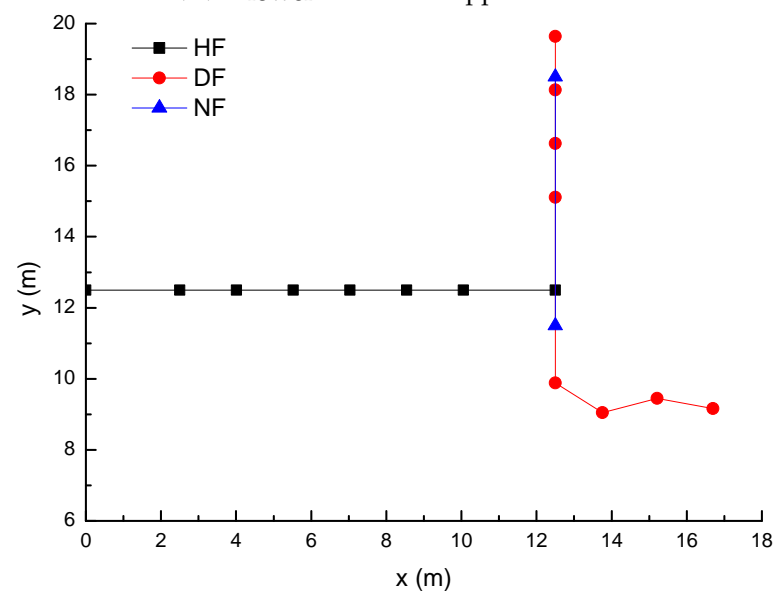

(c) $L_{\text {lower }}=1 \mathrm{~m}, L_{\text {upper }}=6 \mathrm{~m}$

Figure 5. The crack propagation paths at different lengths of lower and upper parts of the NF. In this figure, the black, blue, and red dotted lines, respectively, denote the original HF, the initial NF, and the diverted fracture (DF).

The Von-Mises stress distributions are shown in Figure 6, where a blue color represent a relative stress value, while a yellow or red one represent a higher stress value. For all cases of the model, it is shown that there is a small region of stress concentration near the two tips of the original NF, which indicates that a higher pressure is required to divert the opened NF away from the original NF. 


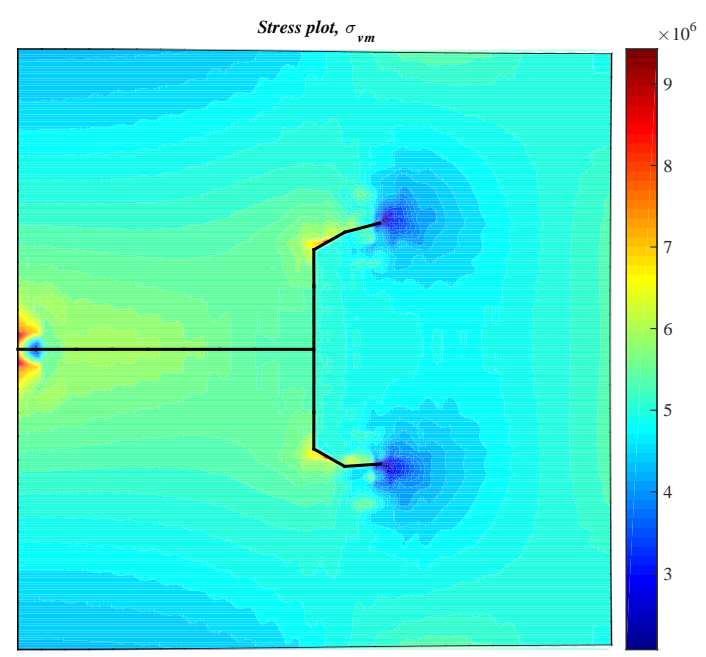

(a) $L_{\text {lower }}=3 \mathrm{~m}, L_{\text {upper }}=4 \mathrm{~m}$

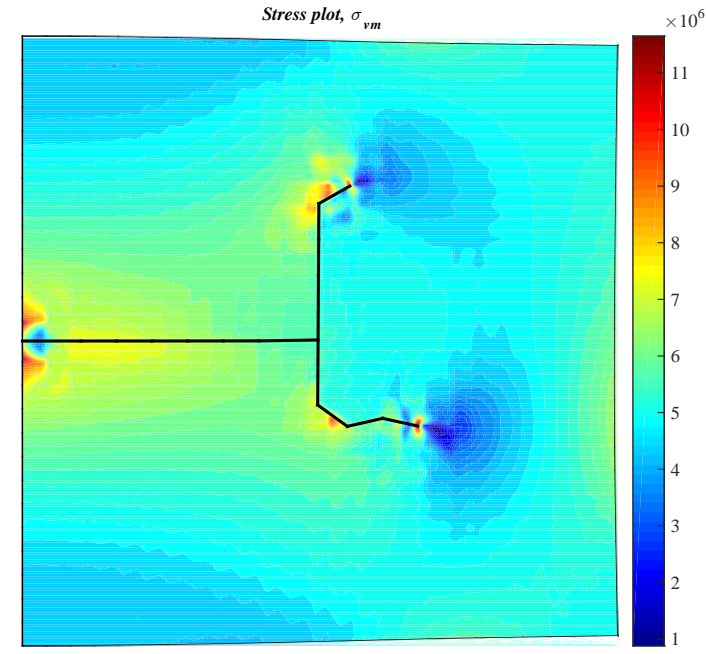

(b) $L_{\text {lower }}=2 \mathrm{~m}, L_{\text {upper }}=5 \mathrm{~m}$

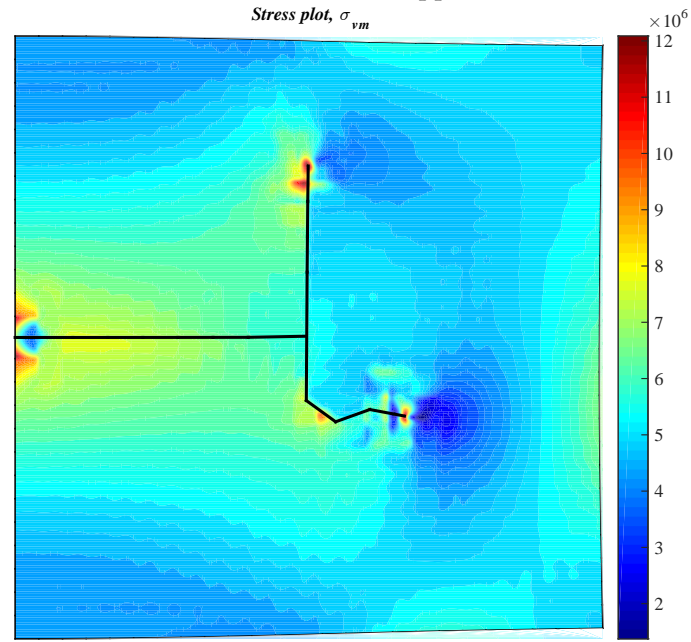

(c) $L_{\text {lower }}=1 \mathrm{~m}, L_{\text {upper }}=6 \mathrm{~m}$

Figure 6. Von-Mises stress distributions at different lengths of lower and upper parts of the NF.

The fracture aperture and net pressure curves of the diverted fracture are shown in Figures 7 and 8 , respectively. With the decrease of $L_{\text {lower }}$, both curves have revealed an asymmetrical characteristic, which peak at the diverted point in the lower parts. In addition, at the intersection point between $\mathrm{HF}$ 
and NF, their corresponding values take second place. The fracture aperture and net pressure in the lower parts of the DF are much greater than those in the upper parts. By comparison, in the case of $L_{\text {lower }}=3 \mathrm{~m}$ and $L_{\text {lower }}=4 \mathrm{~m}$, their curves are nearly symmetrical. This indicates that, under the combined action of remote stress and local crack-tip stress, the variation tendency of the fracture aperture and the net pressure is quite different from that in the case of only a single HF.



Figure 7. The fracture aperture curves of the DF along the fracture length at different lengths of the lower and upper parts of the NF. The distance in the $x$-axis is along the direction from the lower parts to the upper parts of the DF.

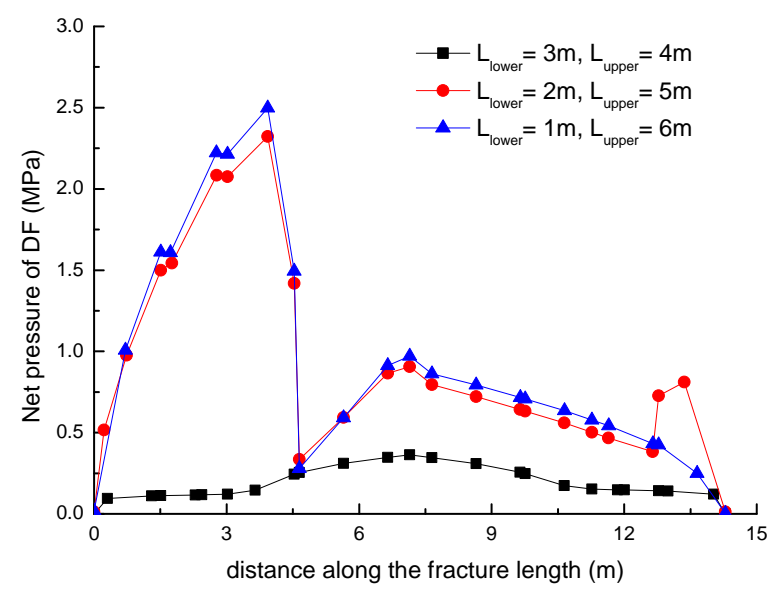

Figure 8. The net pressure curves of the DF along the fracture length at different lengths of the lower and upper parts of the NF. The distance in the $x$-axis is along the direction from the lower parts to the upper parts of the DF.

The flow rate in the diverted fracture is shown in Figure 9. When fluid flows into the intersection point between HF and NF, it will flow upward and downward, respectively. If the value of the flow rate is negative, fluid will flow upward; otherwise, it will flow downward. It is shown that the flow rate in the lower parts of the DF is much greater than that in the upper parts. Therefore, the fracture aperture and net pressure in the lower parts of the DF is greater than that in the upper parts under the condition of the same fluid viscosity. With the decrease of $L_{\text {lower }}$, fluid flows downward more easily. Thus, the lower parts of the original NF is more easily diverted than the upper parts of the original NF. This may explain the results in Figure 5. 


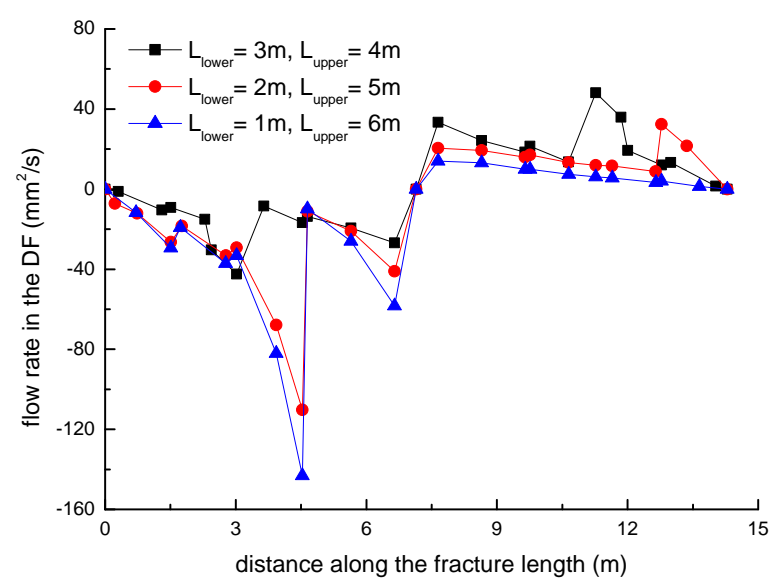

Figure 9. The flow rate curves in the DF along the fracture length at different lengths of the lower and upper parts of the NF. The distance in the $x$-axis is along the direction from the lower parts to the upper parts of the DF.

\subsection{Effect of Horizontal Stress Differences on the Diversion of Fracture Network Propagation}

Based on input parameters in Table 1, the effect of the remote stress difference on the diversion of fracture network propagation is numerically simulated at different levels of minimum horizontal stresses $\sigma_{\mathrm{h}}: 5,4$, and $0 \mathrm{MPa}$; the maximum horizontal stress $\sigma_{\mathrm{H}}$ is kept constant $(5 \mathrm{MPa}$ ) in all cases of this model. At the same time, $L_{\text {lower }}=3 \mathrm{~m}, L_{\text {upper }}=4 \mathrm{~m}$, and the NF-HF intersection angle is equal to $90^{\circ}$.

The corresponding crack propagation paths are shown in Figure 10, in which the deflection angle is defined the angle between NF and DF at the tips of the original NF. According to the data in Figure 10, the deflection angle in the upper parts is calculated. When the horizontal stress difference is, respectively, equal to 0 and $5 \mathrm{MPa}$, the corresponding deflection angle is $59.2^{\circ}$ and $90^{\circ}$, respectively. If the stress difference is increased by $5 \mathrm{MPa}$, the deflection angle in the upper parts is increased by $30.8^{\circ}$. The higher the horizontal stress difference is, the greater the deflection angle is. In Figure 10c, i.e., $\Delta \sigma=5 \mathrm{MPa}$, the opened NF firstly diverts and propagates along the direction of minimum horizontal stress and finally tends to extend along the preferred fracture plane (PFP) direction in petroleum engineering. By contrast, when the stress state is approximately isotropic, crack propagation in both the lower and upper parts will extend along the minimum horizontal stress direction for some length. This indicates that crack propagation of the opened NF is a complex mechanical process under the combined action of the local crack-tip and the remote stress state.

As shown in Figure 11c, there is a lower Von-Mises stress region (corresponding to blue area on the contour) located on the right of DF for $5 \mathrm{MPa}$ stress difference. This propagates the diverted fracture along the PFP. In Figure 11a,b, both cases correspond to a lower stress difference, and the lower stress region is mainly near the two crack tips. The local stress distribution is an explanation to interpret crack paths in Figure 10.

The fracture aperture and net pressure curves of DF are shown in Figures 12 and 13, respectively. The fracture aperture curve reveals an asymmetrical characteristic, while the net pressure curve reveals a nearly symmetrical characteristic. The fracture aperture peaks at a global maximum value at the inflection point, where the opened fracture in the upper parts diverts to the right side in Figure 10; at the NF-HF intersection point, the fracture aperture takes the second place; at the inflection point in the lower parts, it takes the third place. The net pressure reaches a maximum at the intersection point, and there are two inflection points on this curve. This means that the opened fracture diverts to the right side. The higher the stress difference is, the greater the net pressure it requires, which leads to a greater fracture aperture. 


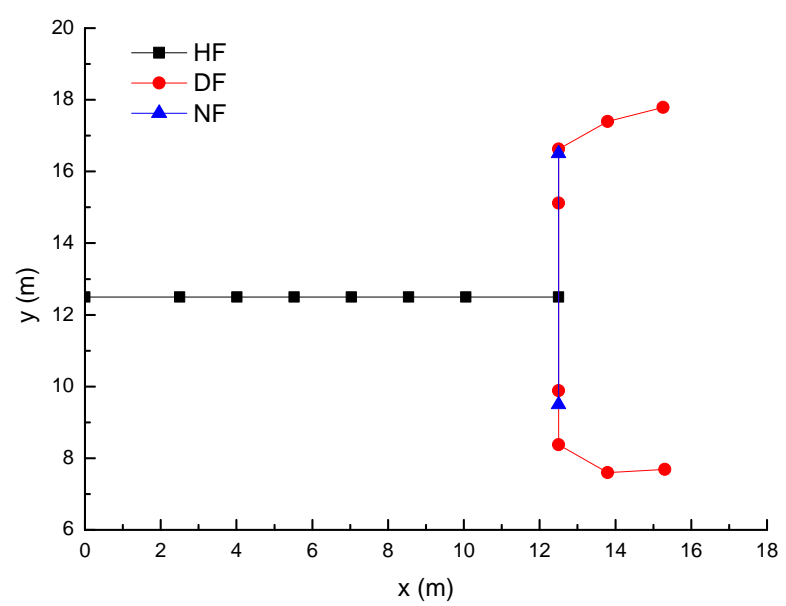

(a) $\sigma_{\mathrm{H}}=5 \mathrm{MPa}, \sigma_{\mathrm{h}}=5 \mathrm{MPa}$

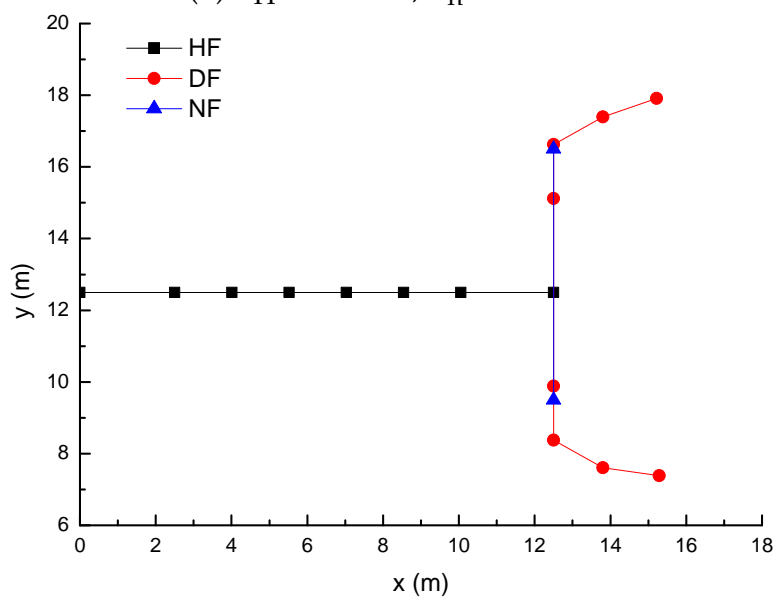

(b) $\sigma_{\mathrm{H}}=5 \mathrm{MPa}, \sigma_{\mathrm{h}}=4 \mathrm{MPa}$

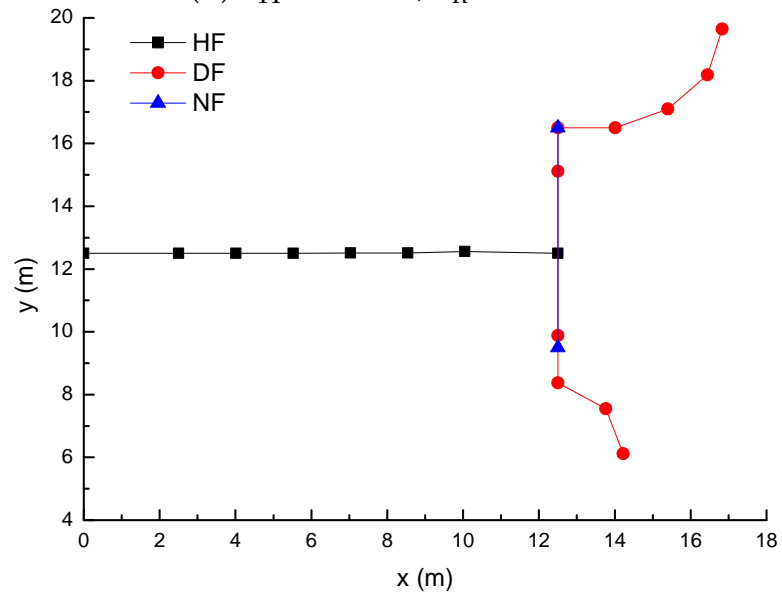

(c) $\sigma_{\mathrm{H}}=5 \mathrm{MPa}, \sigma_{\mathrm{h}}=0 \mathrm{MPa}$

Figure 10. The crack propagation paths at different levels of remote horizontal principle stress difference.

The flow rate in the DF is shown in Figure 14. It is obvious that the flow rate in the upper parts is much greater than that in the lower parts. Therefore, the fracture aperture and net pressure in the upper parts are greater than those in the lower parts for the same fluid viscosity. This might explain the results of fracture aperture and net pressure in Figures 12 and 13. 


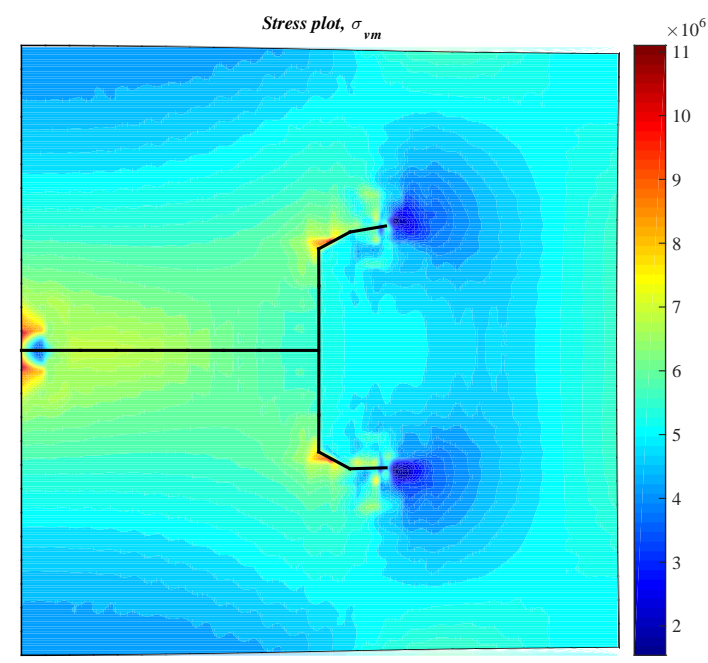

(a) $\sigma_{\mathrm{H}}=5 \mathrm{MPa}, \sigma_{\mathrm{h}}=5 \mathrm{MPa}$



(b) $\sigma_{\mathrm{H}}=5 \mathrm{MPa}, \sigma_{\mathrm{h}}=4 \mathrm{MPa}$

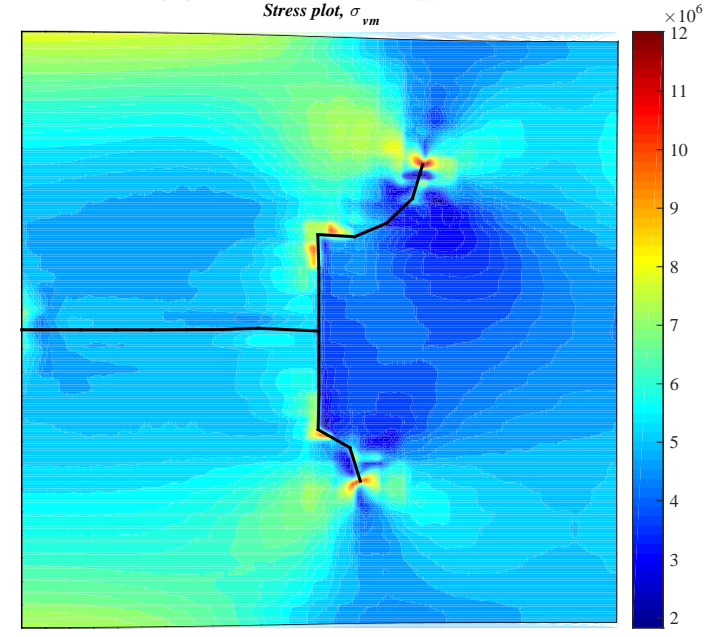

(c) $\sigma_{\mathrm{H}}=5 \mathrm{MPa}, \sigma_{\mathrm{h}}=0 \mathrm{MPa}$

Figure 11. Von-Mises stress distributions at different levels of remote horizontal principle stress difference. 


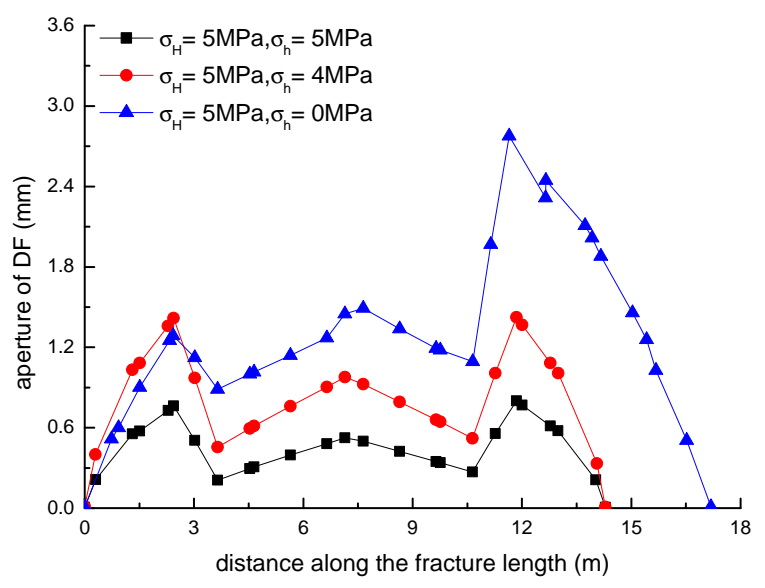

Figure 12. The fracture aperture curves of the DF along the fracture length at different levels of remote horizontal principle stress difference. The distance in the $x$-axis is along the direction from the lower part to the upper part of the DF.

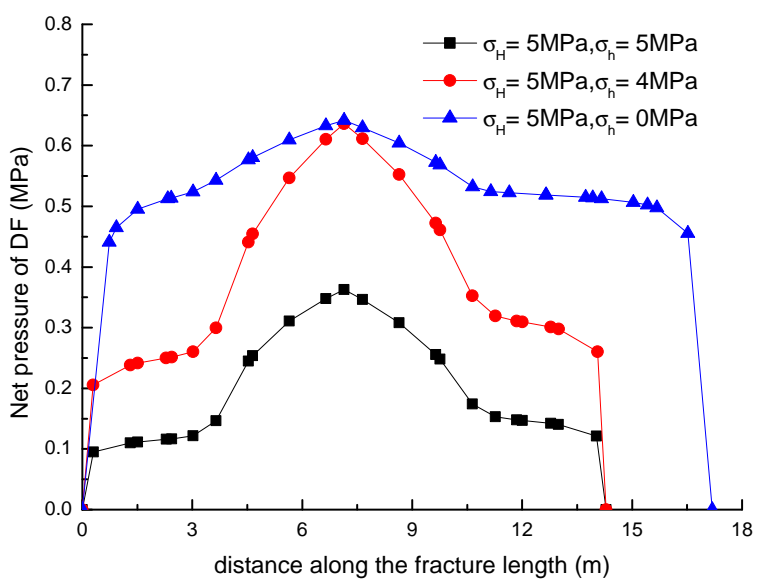

Figure 13. The net pressure curves of the DF along the fracture length at different levels of remote horizontal principle stress difference. The distance in the $x$-axis is along the direction from the lower part to the upper part of the DF.

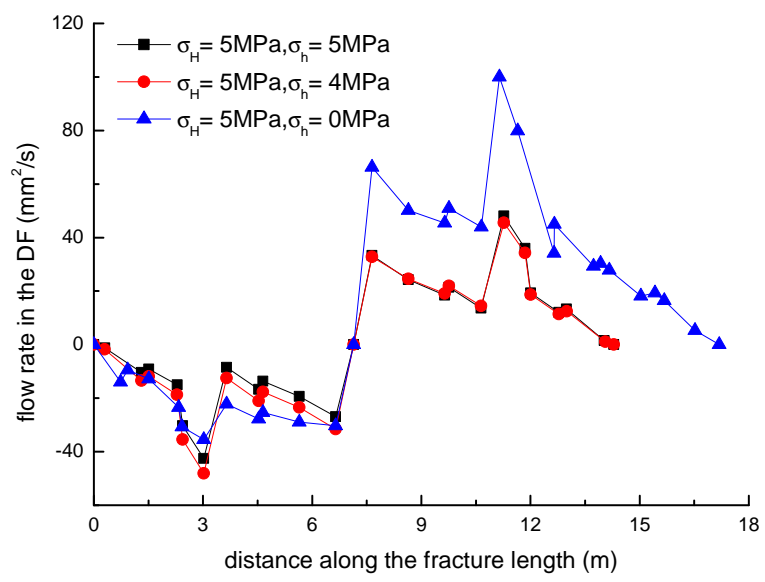

Figure 14. The flow rate curves of the DF along the fracture length at different levels of remote horizontal principle stress difference. The distance in the $x$-axis is along the direction from the lower part to the upper part of the DF. 


\subsection{Effect of the NF-HF Intersection Angle on the Diversion of Fracture Network Propagation}

Based on the input parameters in Table 1, the effect of the NF-HF intersection angle on the diversion of fracture network propagation is numerically simulated at different levels of intersection angles $\beta: 75^{\circ}, 60^{\circ}$, and $45^{\circ}$; both the maximum and minimum horizontal principle stresses are equal to $5 \mathrm{MPa}$ in all cases of this model. Meanwhile, $L_{\text {lower }}$ and $L_{\text {upper }}$ are, respectively, $3 \mathrm{~m}$ and $4 \mathrm{~m}$.

The corresponding crack propagation paths are as shown in Figure 15. Under the condition of isotropic stress state, the NF-HF intersection angle will have a significant impact on the propagation direction of the primary HF, i.e., the black dotted line in Figure 15, when HF is approaching NF. With the decrease of the intersection angle, the primary HF deflects from the horizontal line. When the NF-HF intersection angle is greater than $60^{\circ}$ (in Figure 15a,b), the opened NF in the upper parts is more easily diverted away from the original NF than that in the lower parts under the combined action of remote stress and the crack-tip stress field. However, the intersection angle is less than $60^{\circ}$ (in Figure 15c). The opened NF in the lower parts is more easily diverted away from the original NF than that in the upper parts under the combined action of remote stress and the crack-tip stress field. By making use of the data in Figure 15, the deflection angle for the primary HF was calculated. When the intersection angle is decreased from $75^{\circ}$ to $45^{\circ}$, the corresponding deflection angle is increased from $0^{\circ}$ to $61.2^{\circ}$. This indicates that the NF-HF intersection angle will have a significant impact on the diversion propagation of the primary HF and the secondary opened NFs.

The Von-Mises stress distributions at different levels of NF-HF intersection angle are shown in Figure 16. In Figure 16a, there is a stress concentration region near the diversion point in the upper parts of the NF, which indicates that it will require a high net pressure to divert the opened fracture upward. In Figure 16b, the Von-Mises stress in the upper parts is greater than that in the lower parts, which causes the subsequent fracture to easily divert upward. In Figure 16c, the Von-Mises stress on the left of the NF is greater than that on the right, so it is more easily diverted downward.

The fracture aperture and net pressure curves of the DF are shown in Figures 17 and 18, respectively. In the case of $\beta=75^{\circ}$, the fracture aperture and net pressure in the upper parts is greater than that in the lower parts. In particular, the fracture aperture and net pressure near the diversion point in the lower parts is close to zero, and this is consistent with the results of Von-Mises stress at this point. In the other two cases, the maximum values of the fracture aperture and the net pressure are at the diversion point in the lower parts. The smaller the intersection angle is, the greater the net pressure it requires to divert the fracture.

The flow rate in DF is shown in Figure 19. It is obvious that, in the case of $\beta=45^{\circ}$, the flow rate in the upper parts is much greater than that in the lower parts. This indicates that it is easy for fracturing fluid to flow upward when the intersection angle is small. This is a possible reason for explaining the results in Figures 17 and 18.

\subsection{Effect of Fluid Viscosity on the Diversion of Fracture Network Propagation}

Based on the input parameters in Table 1, the effect of the viscosity of fracturing fluid on the diversion of fracture network propagation is numerically simulated at different levels of viscosity $\mu: 100 \mathrm{mPa} \cdot \mathrm{s}, 10 \mathrm{mPa} \cdot \mathrm{s}$, and $1 \mathrm{mPa} \cdot \mathrm{s}$ [62]. In this model, the maximum and minimum horizontal stresses are kept constant ( $5 \mathrm{MPa}$ ) for all cases. Meanwhile, the NF-HF intersection angle is equal to $90^{\circ}$.

The corresponding crack propagation paths are shown in Figure 20. By making use of the data in Figure 20, the length of DF is calculated. When the fluid viscosity is increased from $100 \mathrm{mPa} \cdot \mathrm{s}$ to $1 \mathrm{mPa} \cdot \mathrm{s}$, the length of DF is increased from 14.29 to $5.23 \mathrm{~m}$. It is clear that the smaller the viscosity is, the more difficult the opened fracture diverts into a new direction. When the viscosity is equal to $1 \mathrm{mPa} \cdot \mathrm{s}$, artificial fracture will propagate along the NF direction under given conditions. This indicates that more energy is required to divert the opened NF upward and downward. 




(a) Intersection angle $\beta=75^{\circ}$

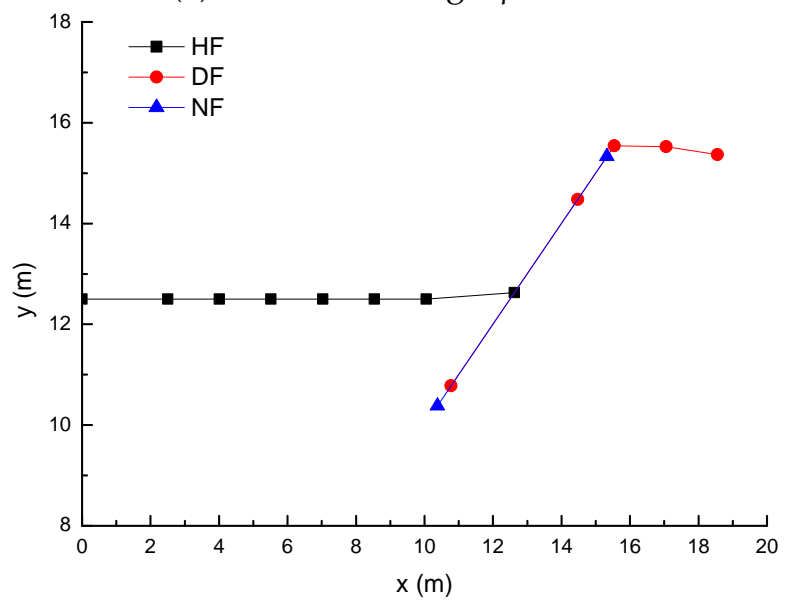

(b) Intersection angle $\beta=60^{\circ}$

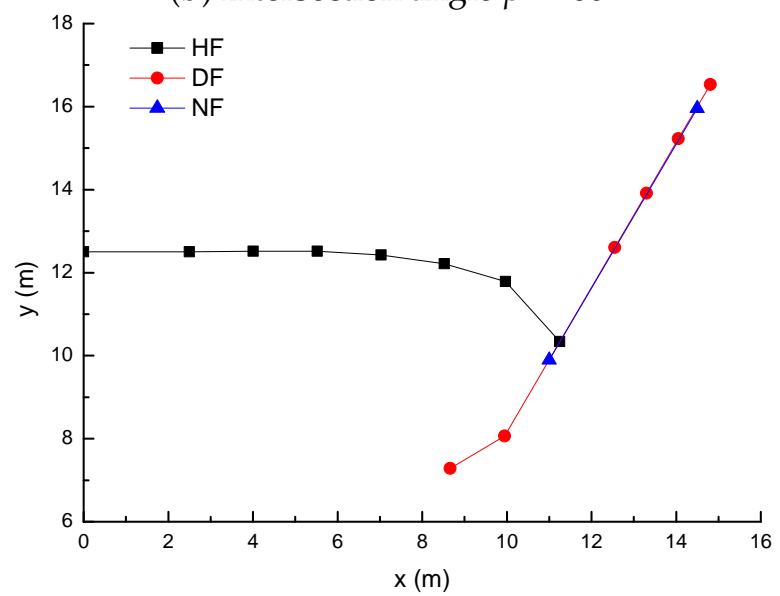

(c) Intersection angle $\beta=45^{\circ}$

Figure 15. The crack propagation paths at different levels of intersection angle between HF and NF. 


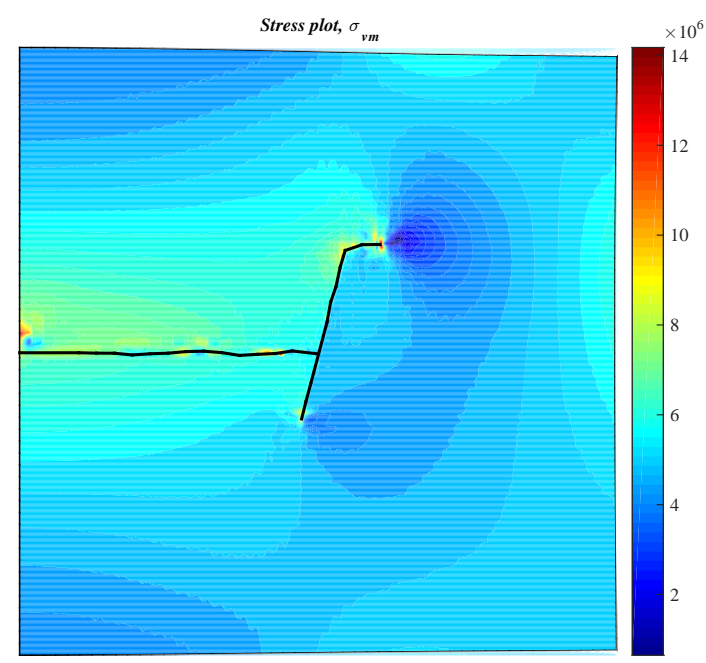

(a) Intersection angle $\beta=75^{\circ}$

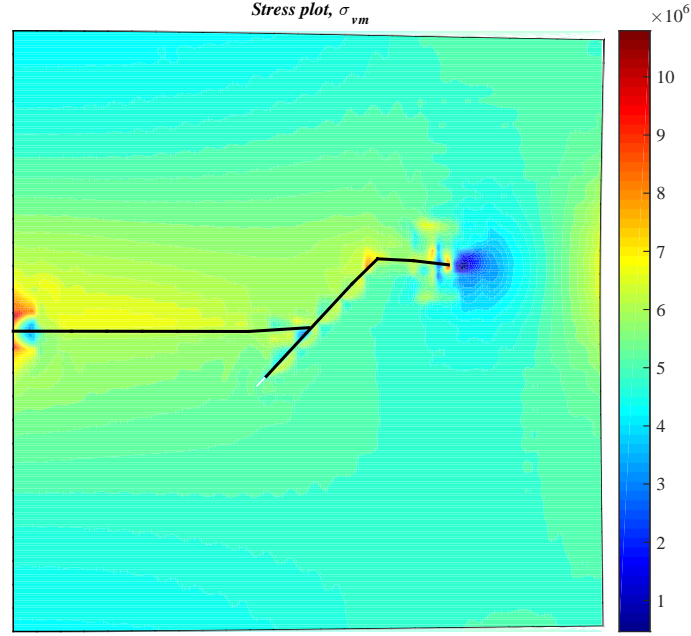

(b) Intersection angle $\beta=60^{\circ}$

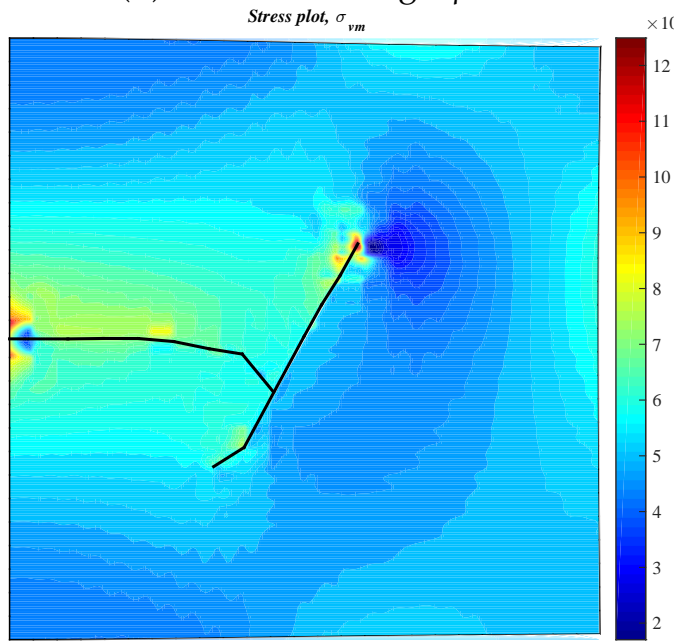

(c) Intersection angle $\beta=45^{\circ}$

Figure 16. Von-Mises stress distributions at different levels of intersection angle between HF and NF. 


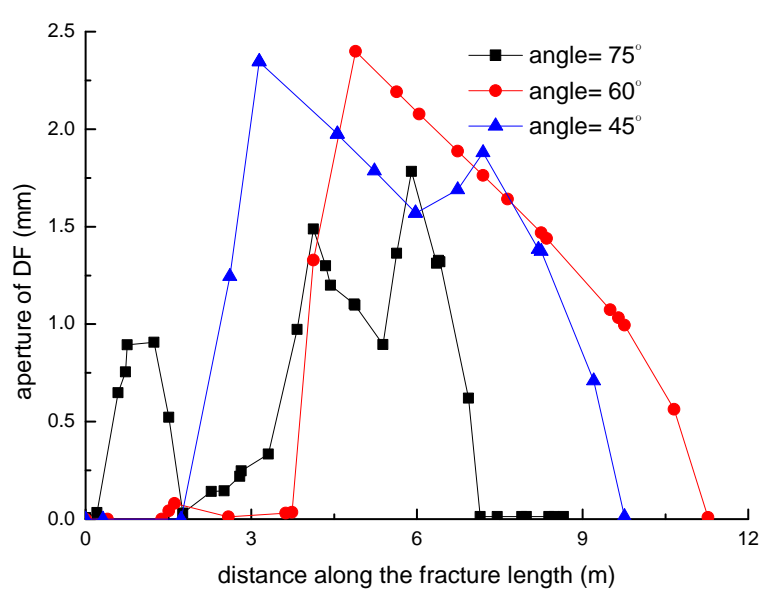

Figure 17. The fracture aperture curves of the DF along the fracture length direction at different levels of intersection angle between HF and NF. The distance in the $x$-axis is along the direction from the lower part to the upper part of the DF.

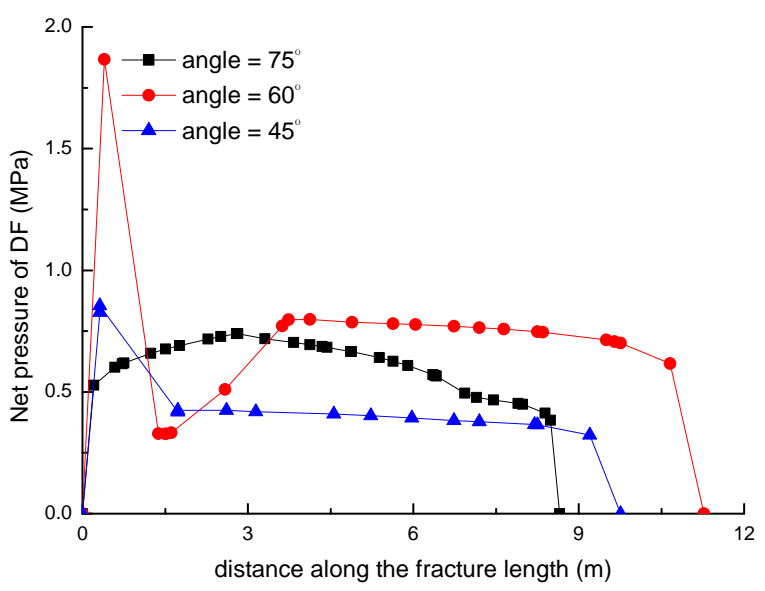

Figure 18. The net pressure curves of the DF along the fracture length direction at different levels of intersection angle between HF and NF. The distance in the $x$-axis is along the direction from the lower part to the upper part of the DF.

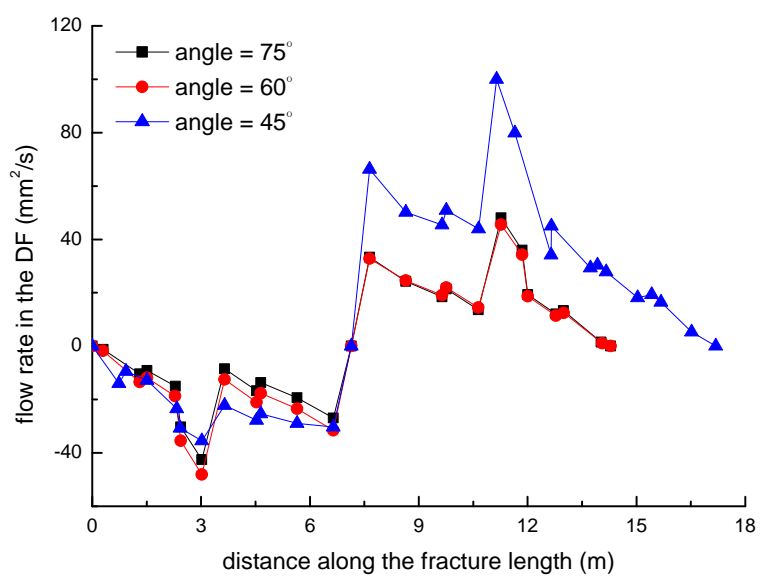

Figure 19. The flow rate curves of the DF along the fracture length direction at different levels of intersection angle between HF and NF. The distance in the $x$-axis is along the direction from the lower part to the upper part of the DF. 


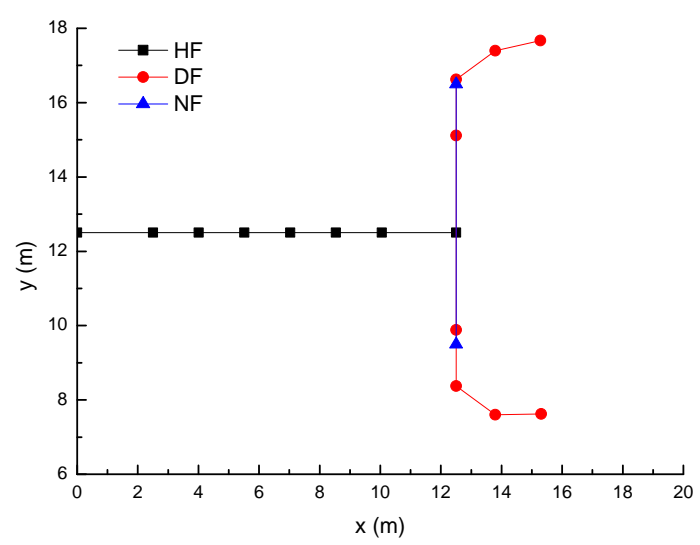

(a) Viscosity $\mu=100 \mathrm{mPa} \cdot \mathrm{s}$

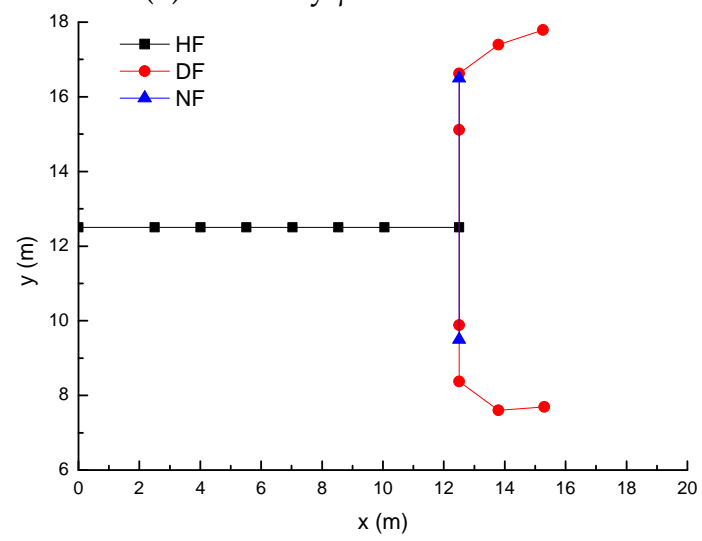

(b) Viscosity $\mu=10 \mathrm{mPa} \cdot \mathrm{s}$

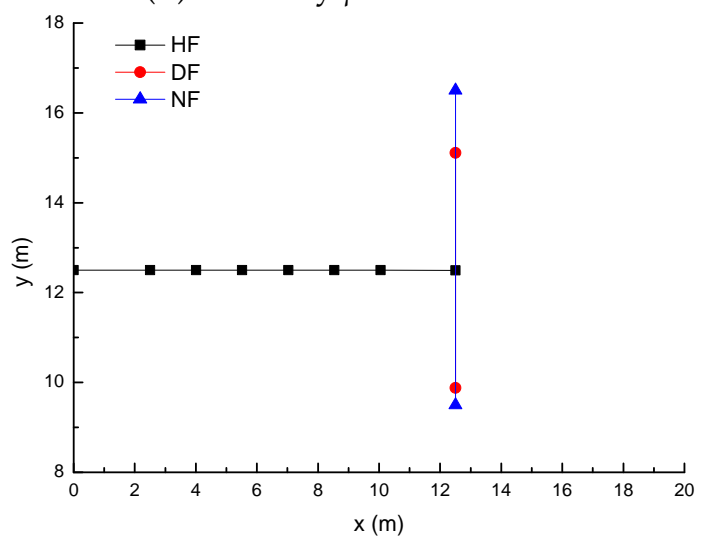

(c) Viscosity $\mu=1 \mathrm{mPa} \cdot \mathrm{s}$

Figure 20. The crack propagation paths at different levels of viscosity of fracturing fluid.

The Von-Mises stress distributions at different levels of fluid viscosity are shown in Figure 21. In Figure 21c, there is a lower Von-Mises stress area on the right of the NF, which makes the opened NF propagate along the original NF direction. This is consistent with the results in Figure 20.

The fracture aperture and net pressure curves of the DF are shown in Figures 22 and 23, respectively. They are close to symmetrical about the axis of the original HF under the condition of an isotropic stress state. In the cases of $\mu=100 \mathrm{mPa} \cdot \mathrm{s}$ and $\mu=10 \mathrm{mPa} \cdot \mathrm{s}$, there are two inflection points on the curves, which correspond to the diversion point in the lower and upper parts of the NF. The greater the fluid viscosity is, the greater the fracture aperture and net pressure are.

The flow rate in the DF is as shown in Figure 24. Obviously, the greater the viscosity is, the greater the flow rate is, and thus the easier it is for the secondary fracture to divert. This might explain the results in Figures 20 and 21 [63]. 


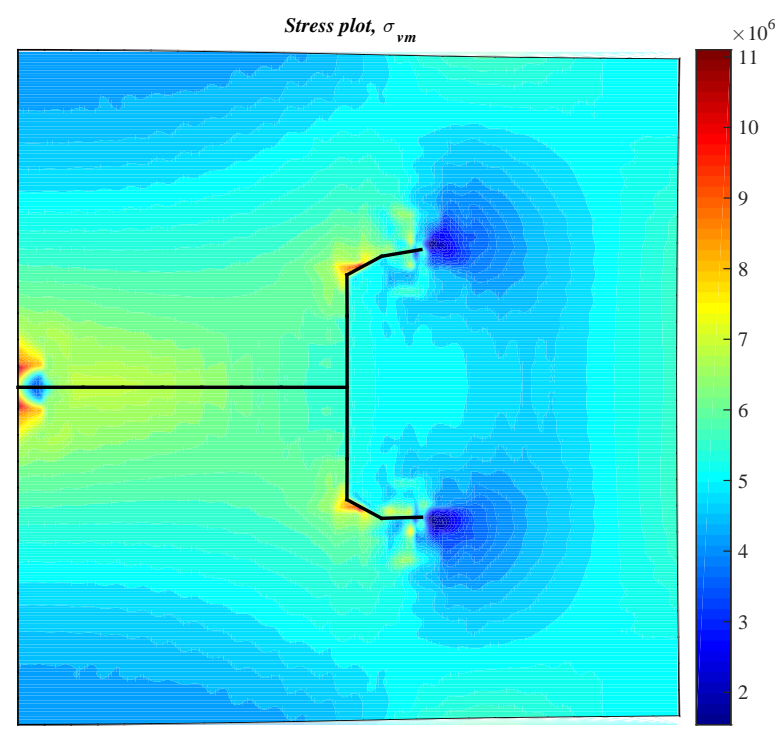

(a) Viscosity $\mu=100 \mathrm{mPa} \cdot \mathrm{s}$

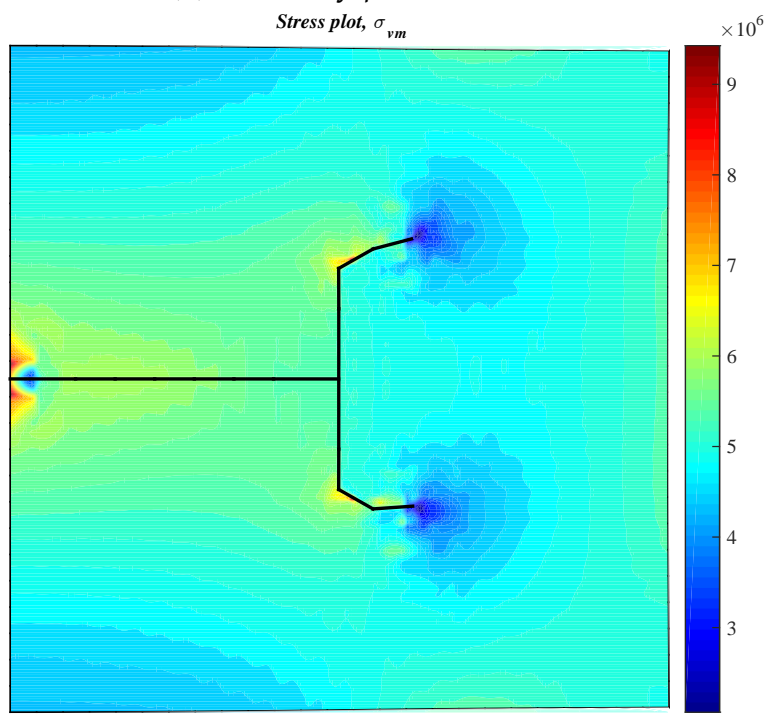

(b) Viscosity $\mu=10 \mathrm{mPa} \cdot \mathrm{s}$

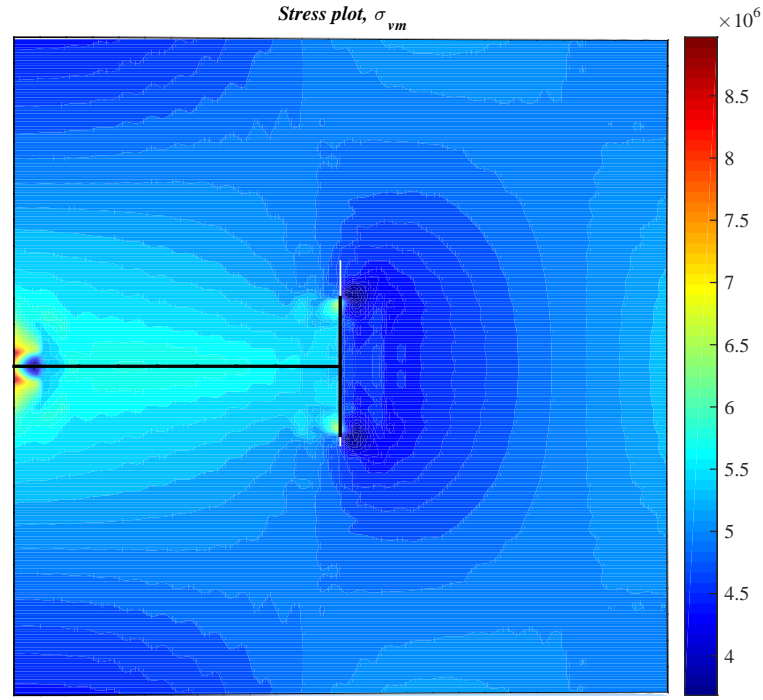

(c) Viscosity $\mu=1 \mathrm{mPa} \cdot \mathrm{s}$

Figure 21. Von-Mises stress distributions at different levels of viscosity of fracturing fluid. 


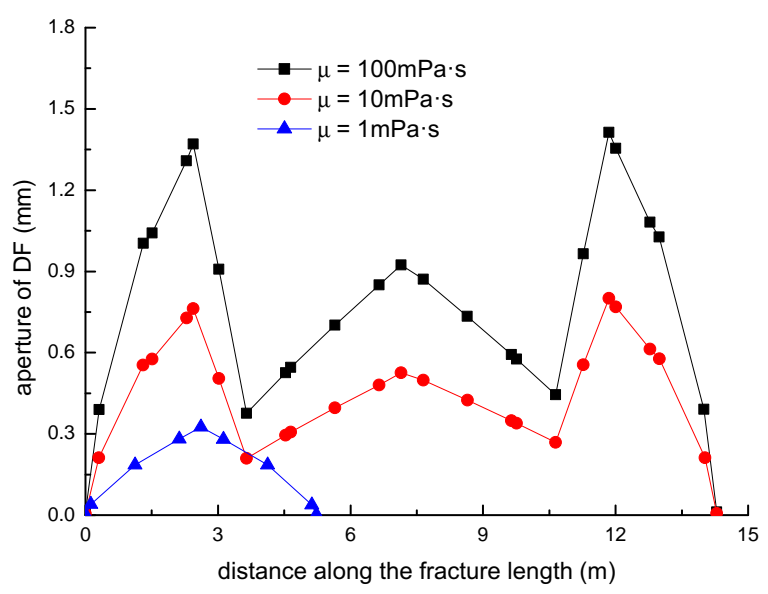

Figure 22. The fracture aperture curves of the DF along the fracture length at different levels of viscosity of fracturing fluid. The distance in the $x$-axis is along the direction from the lower part to the upper part of the DF.



Figure 23. The net pressure curves of the DF along the fracture length at different levels of viscosity of fracturing fluid. The distance in the $x$-axis is along the direction from the lower part to the upper part of the DF.

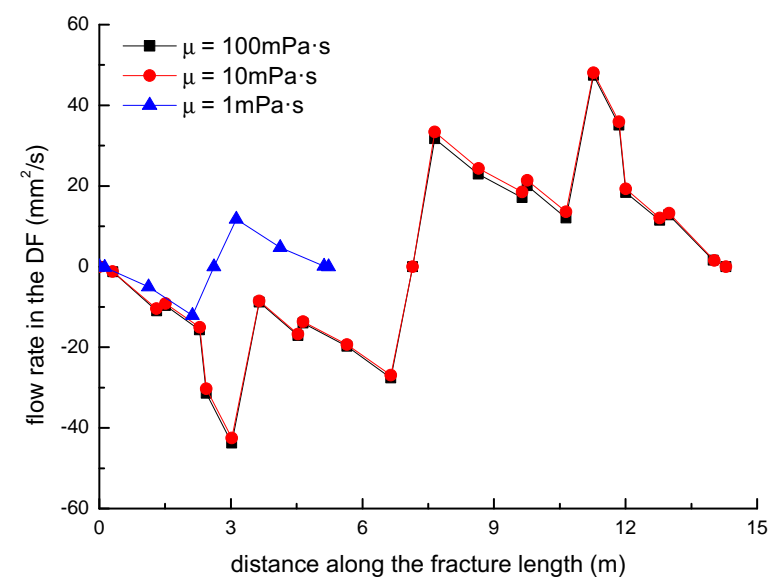

Figure 24. The flow rate curves of the DF along the fracture length direction at different levels of viscosity of fracturing fluid. The distance in the $x$-axis is along the direction from the lower part to the upper part of the DF. 


\section{Conclusions}

This paper investigates the diversion mechanisms of a fracture network in tight formations with frictional NFs by means of the XFEM technique. The effects of some key factors such as the location of the NF, the intersection angle between the NF and HF, the horizontal stress difference, and the fluid viscosity on the mechanical diversion behavior of the HF were analyzed in detail. The following main conclusions can be drawn:

(1) Fracture diversion propagation will occur near the two tips of the opened NF after an HF is intersecting with an NF. The numerical results show that some key factors such as the NF position, the NF-HF intersection angle, the horizontal stress differences, and the fluid viscosity have a significant impact on the diversion propagation in the upper and lower parts of the opened NF.

(2) For a constant length of NF (7 m), the upper length of the DF decreases by about $2 \mathrm{~m}$ with a $2 \mathrm{~m}$ increment of the upper length of the NF $\left(L_{\text {upper }}\right)$, while the length of the DF increases $9.06 \mathrm{~m}$, with the fluid viscosity increased from 1 to $100 \mathrm{mPa} . \mathrm{s}$; (2) the deflection angle in the upper parts increases by $30.8^{\circ}$ with the stress difference increased by $5 \mathrm{MPa}$, while the deflection angle increases by $61.2^{\circ}$ with the intersection angle decreased from $75^{\circ}$ to $45^{\circ}$.

(3) The longer the upper parts of the original NF are, the more difficult it is for the opened NF to divert away from the upper tip of the NF under the conditions of an isotropic stress state, while the lower parts of the original NF is more easily diverted to the right-hand side than the upper parts of the original NF. The NF-HF intersection angle will have a significant impact on the diversion propagation of the primary HF and the secondary opened NFs.

(4) In general, the distributions of fracture aperture, net pressure, and flow rate reveal asymmetrical characteristics for the secondary hydraulically driven fractures. For the distribution of Von-Mises stress, there is usually a concentrated stress zone area near the turning point of the secondary cracks, which corresponds to the inflection points on the curves of the fracture aperture and net pressure.

(5) The diversion mechanisms of the fracture network are the results of the combined action of all factors. This will provide a new perspective on the mechanisms of fracture network generation. Future work should determine the primary and secondary relations of various factors by means of experiments and numerical calculation.

Author Contributions: D.W., F.S., and B.Y. conceived and designed the model of hydraulic fracturing problem using a XFEM technique. D.S., X.L., D.H. and Y.T. analyzed the data. D.W. wrote the paper.

Funding: The authors would like to give their sincere gratitude to the National Science Foundation of China (Nos.51804033 and 51706021), the Beijing Postdoctoral Research Foundation (2018-ZZ-045), the Project of Construction of Innovative Teams and Teacher Career Development for Universities and Colleges Under Beijing Municipality (No. IDHT20170507), the Program of Great Wall Scholar (No. CIT\&TCD20180313), Jointly Projects of Beijing Natural Science Foundation and Beijing Municipal Education Commission (No. KZ201810017023), and the Natural Science Foundation of Jiangsu Province (No. BK20170457) for their financial support.

Conflicts of Interest: The authors declare no conflicts of interest.

\section{Abbreviations}

The following abbreviations are used in this manuscript:

XFEM Extended Finite Element Method

DEM Discrete Element Method

NMM Numerical Manifold Method

SRV Stimulated Reservoir Volume

HF Hydraulic Fracture or Hydraulically Driven Fracture or Hydro-Fracture

NF Natural Fracture

DF Diverted Fracture

PFP Preferred Fracture Plane

ELP Enhanced Local Pressure 


\section{Appendix A}

The result of XEFM is here compared with results of analytical solutions. As is known, depending on the dimensionless fracture toughness, the analytical solutions of the Kristianovich-Geertsma-de Klerk (KGD) model have different expressions. The dimensionless fracture toughness can be written as

$$
K_{m}=4 \sqrt{\frac{2}{\pi}} \frac{K_{I C}\left(1-v^{2}\right)}{E}\left(\frac{E}{12 \mu Q_{0}\left(1-v^{2}\right)}\right)^{1 / 4},
$$

where $K_{m}$ denotes the dimensional fracture toughness; $K_{I C}$ denotes the rock fracture toughness; $\mu$ denotes the viscosity of fracturing fluid; $Q_{0}$ denotes the injection rate; $E$ denotes the rock Young's modulus; $v$ denotes the Poisson's ratio of the rock matrix. If $K_{m}$ is greater than 4 , the fracture propagation regime is toughness dominated; if $K_{m}$ is less than 1, the fracture propagation regime is viscosity dominated, which is much more common in most hydraulic fracturing treatments.

The input parameters of the verification model are listed in Table A1. According to Equation (A1), the dimensionless fracture toughness is equal to 0.313 , which indicates that the fracture propagation regime is viscosity-dominated. In this model, the HF is located at the center of a symmetrical model with a length of $100 \mathrm{~m}$ and $180 \mathrm{~m}$ along the $x$ - and $y$-direction directions, respectively. The domain is divided into 3080 bilinear quadrilateral elements.

Table A1. Input parameter values of hydro-fracturing.

\begin{tabular}{ll}
\hline Input Parameter & Value \\
\hline Young's Modulus, $E$ & $20 \mathrm{GPa}$ \\
Poisson's ratio, $v$ & 0.2 \\
Fracture toughness, $K_{\mathrm{IC}}$ & $0.1 \mathrm{MPa} \cdot \mathrm{m}^{\frac{1}{2}}$ \\
The consistency index of fracturing fluid, $K$ & $0.84 \mathrm{~Pa} \cdot \mathrm{s}^{\mathrm{n}}$ \\
Injection rate, $Q_{0}$ & $0.001 \mathrm{~m} \mathrm{~m}^{2} / \mathrm{s}$ \\
Viscosity, $\mu$ & $0.1 \mathrm{~Pa} \cdot \mathrm{s}$ \\
Dimensionless fracture toughness, $K_{m}$ & 0.313 \\
Injection time, $t$ & $30 \mathrm{~s}$ \\
\hline
\end{tabular}

The initial half-length of the HF is equal to $1.25 \mathrm{~m}$, and it is assumed that a constant fluid pressure acting on the fracture wall is equal to $3.9 \mathrm{MPa}$. The curves of fluid pressure at the injection point and the fracture width at $30 \mathrm{~s}$ are shown in Figure A1a,b, respectively, which is compared with the corresponding analytical solutions. There is very good agreement between the numerical results and analytical solutions, which indicates that the XFEM model can obtain reliable results.

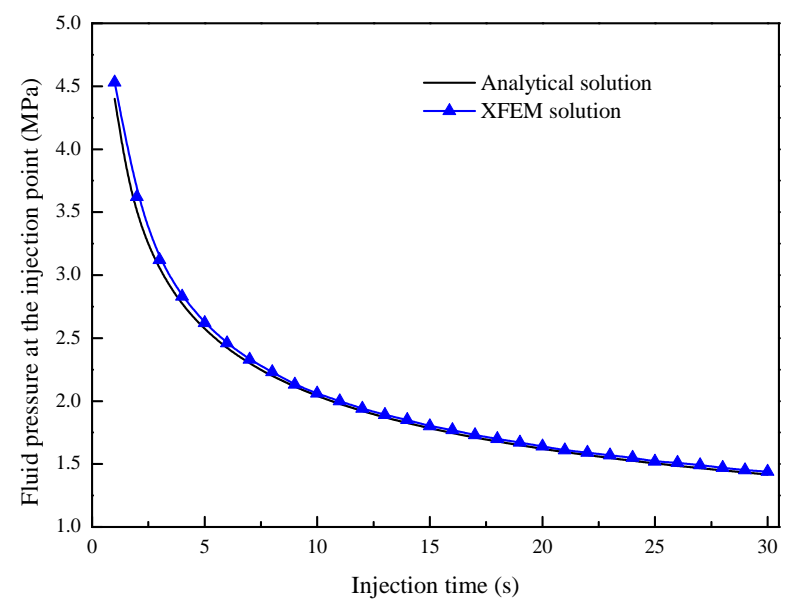

(a) Fluid pressure at the injection point.

Figure A1. Cont. 


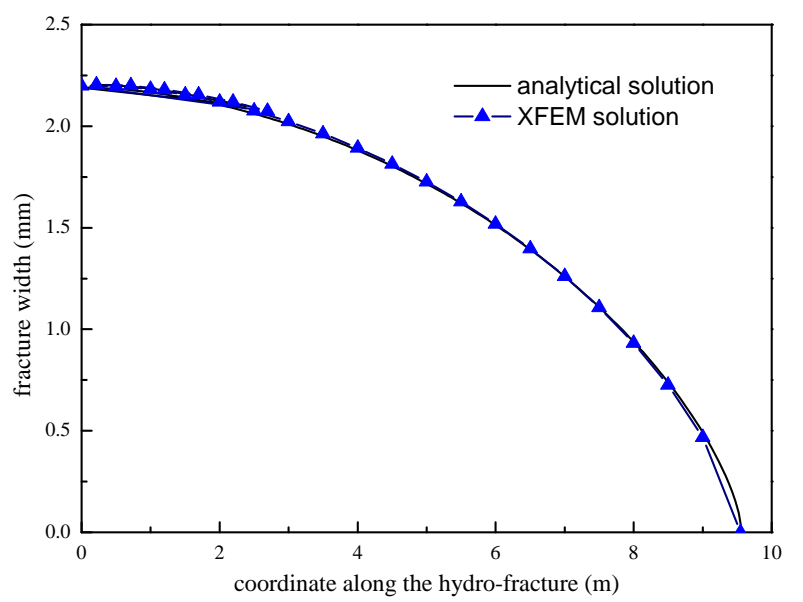

(b) Fracture width.

Figure A1. Results of the XFEM technique and of the analytical solutions.

\section{References}

1. Pang, Y.; Soliman, M.Y.; Deng, H.; Emadi, H. Analysis of effective porosity and effective permeability in shale-gas reservoirs with consideration of gas adsorption and stress effects. SPE J. 2017, 22, 1739-1759. [CrossRef]

2. Shen, Y.; Ge, H.; Li, C.; Yang, X.; Ren, K.; Yang, Z.; Su, S. Water imbibition of shale and its potential influence on shale gas recovery-A comparative study of marine and continental shale formations. J. Nat. Gas Sci. Eng. 2016, 35, 1121-1128. [CrossRef]

3. Pang, Y.; Soliman, M.; Deng, H.; Emadi, H. Effect of methane adsorption on stress-dependent porosity and permeability in shale gas reservoirs. In Proceedings of the SPE Low Perm Symposium, Denver, CO, USA, 5-6 May 2016.

4. Matsunaga, I.; Kobayashi, H.; Sasaki, S.; Ishida, T. Studying hydraulic fracturing mechanism by laboratory experiments with acoustic emission monitoring. In Proceedings of the 34th U.S. Symposium on Rock Mechanics (USRMS), Madison, WI, USA, 28-30 June 1993.

5. Wang, W.; Su, Y.; Sheng, G.; Cossio, M.; Shang, Y. A mathematical model considering complex fractures and fractal flow for pressure transient analysis of fractured horizontal wells in unconventional oil reservoirs. J. Nat. Gas Sci. Eng. 2015, 23, 139-147. [CrossRef]

6. Zhang, J.; Ouyang, L.; Zhu, D.; Hill, A. Experimental and numerical studies of reduced fracture conductivity due to proppant embedment in the shale reservoir. J. Pet. Sci. Eng. 2015, 130, 37-45. [CrossRef]

7. Wang, W.; Shahvali, M.; Su, Y. Analytical solutions for a quad-Linear flow model derived for multistage fractured horizontal wells in tight oil reservoirs. J. Energy Resour. Technol. 2017, 139, 012905. [CrossRef]

8. Wang, W.; Shahvali, M.; Su, Y. A semi-analytical model for production from tight oil reservoirs with hydraulically fractured horizontal wells. Fuel 2015, 158, 612-618. [CrossRef]

9. Cai, J.; Wei, W.; Liu, R.; Wang, J. Fractal characterization of dynamic fracture network extension in porous media. Fractals 2017, 25, 1750023. [CrossRef]

10. Wang, F.; Yang, K.; Cai, J. Fractal characterization of tight oil reservoir pore structure using nuclear magnetic resonance and mercury intrusion porosimetry. Fractals 2018, 26, 1840017. [CrossRef]

11. Singh, H.; Cai, J. Screening improved recovery methods in tight-oil formations by injecting and producing through fractures. Int. J. Heat Mass Transf. 2018, 116, 977-993. [CrossRef]

12. Detournay, E.; Cheng, A.D.; Roegiers, J.C.; McLennan, J. Poroelasticity considerations in In Situ stress determination by hydraulic fracturing. Int. J. Rock Mech. Min. Sci. Geomech. Abstr. 1989, 26, 507-513. [CrossRef]

13. Schmitt, D.; Zoback, M. Poroelastic effects in the determination of the maximum horizontal principal stress in hydraulic fracturing tests-A proposed breakdown equation employing a modified effective stress relation for tensile failure. Int. J. Rock Mech. Min. Sci. Geomech. Abstr. 1989, 26, 499-506. [CrossRef]

14. Mahrer, K.D. A review and perspective on far-field hydraulic fracture geometry studies. J. Pet. Sci. Eng. 1999, 24, 13-28. [CrossRef] 
15. Yew, C.H.; Weng, X. Mechanics of Hydraulic Fracturing, 2nd ed.; Gulf Professional Publishing: Houston, TX, USA, 2014.

16. Hossain, M.M.; Rahman, M. Numerical simulation of complex fracture growth during tight reservoir stimulation by hydraulic fracturing. J. Pet. Sci. Eng. 2008, 60, 86-104. [CrossRef]

17. Yuan, B.; Zheng, D.; Moghanloo, R.G.; Wang, K. A novel integrated workflow for evaluation, optimization, and production predication in shale plays. Int. J. Coal Geol. 2017, 180, 18-28. [CrossRef]

18. Yuan, B.; Su, Y.; Moghanloo, R.G.; Rui, Z.; Wang, W.; Shang, Y. A new analytical multi-linear solution for gas flow toward fractured horizontal wells with different fracture intensity. J. Nat. Gas Sci. Eng. 2015, 23, 227-238. [CrossRef]

19. Wu, K.; Chen, Z.; Li, X.; Guo, C.; Wei, M. A model for multiple transport mechanisms through nanopores of shale gas reservoirs with real gas effect-adsorption-mechanic coupling. Int. J. Heat Mass Transf. 2016, 93, 408-426. [CrossRef]

20. Wei, B.; Li, Q.; Jin, F.; Wang, C. The potential of a novel nanofluid in enhancing oil recovery. Energy Fuels 2016, 30, 2882-2891. [CrossRef]

21. Zhang, Q.; Su, Y.; Wang, W.; Lu, M.; Sheng, G. Gas transport behaviors in shale nanopores based on multiple mechanisms and macroscale modeling. Int. J. Heat Mass Transf. 2018, 125, 845-857. [CrossRef]

22. Renshaw, C.; Pollard, D. An experimentally verified criterion for propagation across unbounded frictional interfaces in brittle, linear elastic materials. Int. J. Rock Mech. Min. Sci. Geomech. Abstr. 1995, 32, 237-249. [CrossRef]

23. Gu, H.; Weng, X. Criterion for fractures crossing frictional interfaces at non-orthogonal angles. In Proceedings of the 44th U.S. Rock Mechanics Symposium and 5th U.S.-Canada Rock Mechanics Symposium, Salt Lake City, UT, USA, 27-30 June 2010.

24. Chen, Z.; Jeffrey, R.G.; Zhang, X.; Kear, J. Finite-element simulation of a hydraulic fracture interacting with a natural fracture. SPE J. 2017, 22, 219-234. [CrossRef]

25. Zou, Y.; Zhang, S.; Ma, X.; Zhou, T.; Zeng, B. Numerical investigation of hydraulic fracture network propagation in naturally fractured shale formations. J. Struct. Geol. 2016, 84, 1-13. [CrossRef]

26. Wu, Z.; Wong, L.N.Y. Frictional crack initiation and propagation analysis using the numerical manifold method. Comput. Geotech. 2012, 39, 38-53. [CrossRef]

27. Heider, Y.; Reiche, S.; Siebert, P.; Markert, B. Modeling of hydraulic fracturing using a porous-media phase-field approach with reference to experimental data. Eng. Fract. Mech. 2018, 202, 116-134. [CrossRef]

28. Dahi-Taleghani, A.; Olson, J.E. Numerical modeling of multistranded-hydraulic-fracture propagation: Accounting for the interaction between induced and natural fractures. SPE J. 2011, 16, 575-581. [CrossRef]

29. Gordeliy, E.; Peirce, A. Enrichment strategies and convergence properties of the XFEM for hydraulic fracture problems. Comput. Methods Appl. Mech. Eng. 2015, 283, 474-502. [CrossRef]

30. Sheng, M.; Li, G.; Shah, S.; Lamb, A.R.; Bordas, S.P. Enriched finite elements for branching cracks in deformable porous media. Eng. Anal. Bound. Elem. 2015, 50, 435-446. [CrossRef]

31. Klimenko, D.; Taleghani, A.D. A modified extended finite element method for fluid-driven fractures incorporating variable primary energy loss mechanisms. Int. J. Rock Mech. Min. Sci. 2018, 106, 329-341. [CrossRef]

32. Sheng, M.; Li, G.; Sutula, D.; Tian, S.; Bordas, S.P. XFEM modeling of multistage hydraulic fracturing in anisotropic shale formations. J. Pet. Sci. Eng. 2018, 162, 801-812. [CrossRef]

33. Shi, F.; Wang, X.; Liu, C.; Liu, H.; Wu, H. An XFEM-based method with reduction technique for modeling hydraulic fracture propagation in formations containing frictional natural fractures. Eng. Fract. Mech. 2017, 173, 64-90. [CrossRef]

34. Wang, X.; Shi, F.; Liu, C.; Lu, D.; Liu, H.; Wu, H. Extended finite element simulation of fracture network propagation in formation containing frictional and cemented natural fractures. J. Nat. Gas Sci. Eng. 2018, 50, 309-324. [CrossRef]

35. Ghaderi, A.; Taheri-Shakib, J.; Mohammad Nik, A.S. The distinct element method (DEM) and the extended finite element method (XFEM) application for analysis of interaction between hydraulic and natural fractures. J. Pet. Sci. Eng. 2018, 171, 422-430. [CrossRef]

36. Paul, B.; Faivre, M.; Massin, P.; Giot, R.; Colombo, D.; Golfier, F.; Martin, A. 3D coupled HM-XFEM modeling with cohesive zone model and applications to non planar hydraulic fracture propagation and multiple hydraulic fractures interference. Comput. Methods Appl. Mech. Eng. 2018, 342, 321-353. [CrossRef] 
37. Remij, E. Wand Remmers, J.J.C.; Huyghe, J.M.; Smeulders, D.M.J. On the numerical simulation of crack interaction in hydraulic fracturing. Comput. Geosci. 2018, 22, 423-437. [CrossRef]

38. Vahab, M.; Khalili, N. X-FEM modeling of multizone hydraulic fracturing treatments within saturated porous media. Rock Mech. Rock Eng. 2018, 51, 3219-3239. [CrossRef]

39. Wang, D.; Zhou, F.; Ding, W.; Ge, H.; Jia, X.; Shi, Y.; Wang, X.; Yan, X. A numerical simulation study of fracture reorientation with a degradable fiber-diverting agent. J. Nat. Gas Sci. Eng. 2015, 25, 215-225. [CrossRef]

40. Gravouil, A.; Moës, N.; Belytschko, T. Non-planar 3D crack growth by the extended finite element and level sets-Part II: Level set update. Int. J. Numer. Methods Eng. 2002, 53, 2569-2586. [CrossRef]

41. Taleghani, A.D.; Gonzalez, M.; Shojaei, A. Overview of numerical models for interactions between hydraulic fractures and natural fractures: Challenges and limitations. Comput. Geotech. 2016, 71, 361-368. [CrossRef]

42. Feng, Y.; Li, X.; Gray, K.E. Mudcake effects on wellbore stress and fracture initiation pressure and implications for wellbore strengthening. Pet. Sci. 2018, 15, 319-334. [CrossRef]

43. Olson, J.E.; Bahorich, B.; Holder, J. Examining hydraulic fracture: Natural fracture interaction in hydrostone block experiments. In Proceedings of the SPE Hydraulic Fracturing Technology Conference, Woodlands, TX, USA, 6-8 February 2012.

44. Zhang, Q.; Su, Y.; Wang, W.; Lu, M.; Sheng, G. Apparent permeability for liquid transport in nanopores of shale reservoirs: Coupling flow enhancement and near wall flow. Int. J. Heat Mass Transf. 2017, 115, $224-234$. [CrossRef]

45. Wang, D.; Zhou, F.; Ge, H.; Shi, Y.; Yi, X.; Xiong, C.; Liu, X.; Wu, Y.; Li, Y. An experimental study on the mechanism of degradable fiber-assisted diverting fracturing and its influencing factors. J. Nat. Gas Sci. Eng. 2015, 27, 260-273. [CrossRef]

46. Cherny, S.; Lapin, V.; Esipov, D.; Kuranakov, D.; Avdyushenko, A.; Lyutov, A.; Karnakov, P. Simulating fully 3D non-planar evolution of hydraulic fractures. Int. J. Fract. 2016, 201, 181-211. [CrossRef]

47. Gupta, P.; Duarte, C.A. Coupled hydromechanical-fracture simulations of nonplanar three-dimensional hydraulic fracture propagation. Int. J. Numer. Anal. Methods Geomech. 2018, 42, 143-148. [CrossRef]

48. Zlotnik, S.; Díez, P.; Fernández, M.; Vergés, J. Numerical modelling of tectonic plates subduction using X-FEM. Comput. Methods Appl. Mech. Eng. 2007, 196, 4283-4293. [CrossRef]

49. Wang, T.; Liu, Z.; Zeng, Q.; Gao, Y.; Zhuang, Z. XFEM modeling of hydraulic fracture in porous rocks with natural fractures. Sci. China-Phys. Mech. Astron. 2017, 60, 084612. [CrossRef]

50. Haddad, M.; Sepehrnoori, K. XFEM-Based CZM for the simulation of 3D multiple-cluster hydraulic fracturing in quasi-brittle shale formations. Rock Mech. Rock Eng. 2016, 49, 4731-4748. [CrossRef]

51. Feng, Y.; Gray, K. Modeling of curving hydraulic fracture propagation from a wellbore in a poroelastic medium. J. Nat. Gas Sci. Eng. 2018, 53, 83-93. [CrossRef]

52. Chen, Z. A New Enriched Finite Element Method with Application to Static Fracture Problems with Internal Fluid Pressure. Int. J. Appl. Mech. 2015, 7, 1550037. [CrossRef]

53. Meschke, G.; Leonhart, D. A Generalized Finite Element Method for hydro-mechanically coupled analysis of hydraulic fracturing problems using space-time variant enrichment functions. Comput. Methods Appl. Mech. Eng. 2015, 290, 438-465. [CrossRef]

54. Mohammadnejad, T.; Khoei, A.R. Hydro-mechanical modeling of cohesive crack propagation in multiphase porous media using the extended finite element method. Int. J. Numeri. Anal. Methods Geomech. 2013, 37, 1247-1279. [CrossRef]

55. Taleghani, A.D.; Gonzalez-Chavez, M.; Yu, H.; Asala, H. Numerical simulation of hydraulic fracture propagation in naturally fractured formations using the cohesive zone model. J. Pet. Sci. Eng. 2018, 165, 42-57. [CrossRef]

56. Kumar, D.; Ghassemi, A. Three-Dimensional Poroelastic Modeling of Multiple Hydraulic Fracture Propagation from Horizontal Wells. Int. J. Rock Mech. Min. Sci. 2018, 105, 192-209. [CrossRef]

57. Moës, N.; Dolbow, J.; Belytschko, T. A finite element method for crack growth without remeshing. Int. J. Numer. Methods Eng. 1999, 46, 131-151. [CrossRef]

58. Feng, Y.; Gray, K.E. A fracture-mechanics-based model for wellbore strengthening applications. J. Nat. Gas Sci. Eng. 2016, 29, 392-400. [CrossRef]

59. Khoei, A.R. Extended Finite Element Method: Theory and Applications; John Wiley \& Sons: Hoboken, NJ, USA, 2014. 
60. Gu, H.; Weng, X.; Lund, J.B.; Mack, M.G.; Ganguly, U.; Suarez-Rivera, R. Hydraulic fracture crossing natural fracture at nonorthogonal angles: A criterion and its validation. SPE Prod. Oper. 2012, 27, 20-26. [CrossRef]

61. Jia, B.; Tsau, J.S.; Barati, R. A review of the current progress of CO2 injection EOR and carbon storage in shale oil reservoirs. Fuel 2019, 236, 404-427. [CrossRef]

62. McGinley, M.J. The Effects of Fracture Orientation and Anisotropy on Hydraulic Fracture Conductivity in the Marcellus Shale. Master's Thesis, Texas A\&M University, College Station, TX, USA, 2015. Available online: https:/ / doi.org/http:/ / hdl.handle.net/1969.1/155300 (accessed on 1 September 2018).

63. Jia, B.; Tsau, J.S.; Barati, R. Experimental and numerical investigations of permeability in heterogeneous fractured tight porous media. J. Nat. Gas Sci. Eng. 2018, 58, 216-233. [CrossRef]

(C) 2018 by the authors. Licensee MDPI, Basel, Switzerland. This article is an open access article distributed under the terms and conditions of the Creative Commons Attribution (CC BY) license (http://creativecommons.org/licenses/by/4.0/). 